\title{
A HIDDEN HISTORY OF EARLY COLOUR PHOTOGRAPHY IN BRITAIN: THE PHOTOGRAPHS OF AGNES B. WARBURG (1872-1953)
}

\author{
By \\ Hana Kaluznick \\ A thesis \\ presented to Ryerson University \\ in partial fulfillment of the \\ requirements for the degree of \\ Master of Arts \\ in the program of
}

Bachelor of Arts, Music and Economics, Dalhousie University, 2015

Film and Photography Preservation and Collections Management

Toronto, Ontario, Canada, 2019

(C) Hana Kaluznick, 2019 


\section{AUTHOR'S DECLARATION FOR ELECTRONIC SUBMISSION OF A THESIS}

I hereby declare that I am the sole author of this thesis. This is a true copy of the thesis, including any required final revisions, as accepted by my examiners.

I authorize Ryerson University to lend this thesis to other institutions or individuals for the purpose of scholarly research.

I further authorize Ryerson University to reproduce this thesis by photocopying or by other means, in total or in part, at the request of other institutions or individuals for the purpose of scholarly research.

I understand that my thesis may be made electronically available to the public. 
A Hidden History of Early Colour Photography in Britain: The Photographs of Agnes B. Warburg (1872-1953)

Hana Kaluznick

Master of Arts, 2019, Film and Photography Preservation and Collections Management Ryerson University, Toronto, Canada

\begin{abstract}
Agnes Beatrice Warburg (1872-1953) was a British amateur photographer and active member of the Royal Photographic Society (RPS). The official collection of her works is housed at the Victoria and Albert Museum in London, and totals nearly 1000 black and white and colour photographs. Between about 1890 and 1949, Warburg experimented with nine different colour photographic and printing techniques, established the RPS Colour Group in 1927, and invented her own process called the Wartype in 1918. This thesis will examine the hitherto untold history of Agnes B. Warburg, and narrate a history of early colour photography between 1907 and 1945, using her body of work as a reference. This approach allows us to see how amateur photographic practices informed and perpetuated the artistic and technical development of colour photography in the early $20^{\text {th }}$ century, and in doing so provides us with a deeper understanding of photographic history.
\end{abstract}




\section{Acknowledgements}

I would like to thank my first reader Robert Burley for his time, constructive and insightful feedback, and seemingly endless amount of patience and enthusiasm. Thank you for sharing your knowledge of the history of colour photography with me - it is second to none. I would also like to thank my second reader, Don Snyder.

I am very grateful to everyone in the Photographs section at the V\&A. Thank you for giving me the freedom to explore every inch of this collection and for your encouragement along the way. 


\section{Table of Contents}

Abstract iii

List of Figures vi vi

Introduction 1

Literature Review 5

Chapter 1: History of Colour until 1907

The Study of Light and Colour $\quad 10$

Initial Attempts at Direct Colour $\quad 12$

The Solutions 13

Chapter 2: Agnes B. Warburg (1872-1953) 18

Chapter 3: The Culture of Amateur Photography: 1900-1930 26

Chapter 4: The RPS Colour Group 29

Chapter 5: Colour Processes 33

I. Platinum and Carbon (1890-1900) 35

Additive Screen Processes $\quad 36$

$\begin{array}{ll}\text { II. Autochrome } & 37\end{array}$

$\begin{array}{ll}\text { III. Dufaycolor } & 40\end{array}$

IV. Additive Colour Screen Printing 44

Dye Imbibition Processes $\quad 45$

V. Colorsnap $\quad 45$

Pigment Processes $\quad 47$

VI. Gum Printing 48

VII. Tri-colour Carbro $\quad 50$

VIII. Raydex / Ozobrome

IX. War-type $\quad 56$

$\begin{array}{ll}\text { Conclusion } & 58\end{array}$

$\begin{array}{ll}\text { Bibliography } & 61\end{array}$ 


\section{List of Figures}

Figure 1. Paul Emil Chappuis, [ARtists Model], hand-Tinted daguerreotype, CA. 1861 (C) Victoria

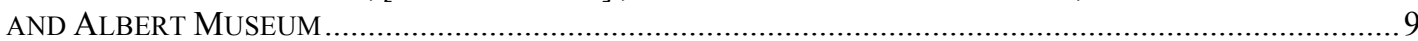

FiguRE 2. D.A. SPENCER, TARTAN RIBBON, VIVEX PROCESS, PRINTED 1933 USING ORIGINAL JAMES CLERK MAXWELL POSITIVE TRANSPARENCIES CREATED IN 1861 @ C VICTORIA AND ALBERT MUSEUM .............11

FIGURE 3. ILLUSTRATION DEMONSTRATING ADDITIVE COLOUR SYNTHESIS ONTO AN IMAGE PLANE. WHEN THE THREE PRIMARY COLOURS ARE PROJECTED, A SPECTRUM OF COLOURS IS CREATED: ADDITION OF ALL THREE COLOURS RESULTS IN WHITE; A MIXTURE OF GREEN AND BLUE PRODUCES CYAN; BLUE AND GREEN PRODUCES MAGENTA; RED AND GREEN PRODUCES YELLOW...

FIGURE 4. ILLUSTRATION DEMONSTRATING SUBTRACTIVE COLOUR SYNTHESIS CREATED THROUGH THE ABSORPTION OF THE THREE PRIMARY COLOURS FROM WHITE LIGHT. WHEN THE SUBTRACTIVE COLOURS, CYAN, YELLOW AND MAGENTA ARE TAKEN FROM A WHITE LIGHT SOURCE THE FOLLOWING COLOURS ARE CREATED: SUBTRACTION OF ALL THREE COLOURS RESULTS IN BLACK; A MIXTURE OF CYAN AND YELLOW PRODUCES GREEN; CYAN AND MAGENTA PRODUCES BLUE; MAGENTA AND YELLOW PRODUCES RED.

Figure 5. AgNes WARBURG, LiLy WARBURG (SISTER), EMMA WARBURG (MOTHER), Violet Sichel (WiFE

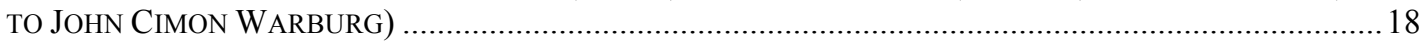

Figure 6. AgNES B. WARBURG, [JOHN C. WARBURG IN THE DARKROOM], CARBON PRINT, CA. 1900 C)

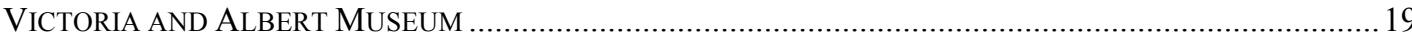

Figure 7. Agnes B. WARBurG, 5527. MALTESE MAIDENS, DUfAYCOlOR, 1938 @ Victoria AND ALBERT

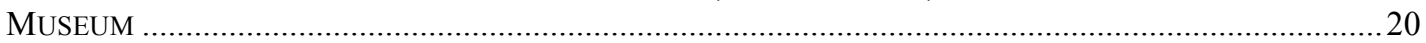

Figure 8. AgNes B. WARBURG, 5311. LUND: THE PURCHASE, DUFAYCOLOR, 1938 C VICTORIA AND ALBERT MUSEUM .

Figure 9. AGNES B. WARBURG, AT THE GARAGE DOOR, VERSO, TRI-COLOUR CARBRO PRINT, 1929. STAMPS INDICATING INTERNATIONAL EXCHANGE LOCATIONS OF PRINT: THE ROYAL PHOTOGRAPHIC SOCIETY, 1926; THE INTERNATIONAL PHOTOGRAPHIC EXHIBITION, 1927, LuCKNOW, INDIA; INTERNATIONAL

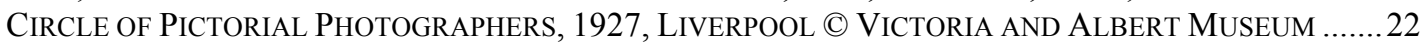

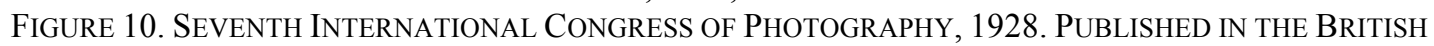
JOURNAL OF PHOTOGRAPHY (AGNES WARBURG, MIDDLE ROW, THIRD FROM THE LEFT; JOHN CIMON WARBURG, FRONT ROW, SECOND FROM THE RIGHT)

FigURE 11. INSTALLATION PHOTOGRAPH OF THE RPS EXHIBITION PHOTOGRAPHY IN THE SERVICE OF MANKIND, 1931, FROM THE PHOTOGRAPHIC JOURNAL, NOVEMBER, 1931 .......................................... 31

Figure 12. AgNes B. WARBURG, OLIVES AND ALMONDS, MAJORCA, TRI-COLOUR CARBRO PRINT, CA. 1930, ()

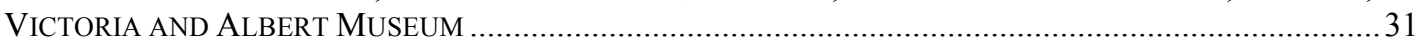

Figure 13. Agnes B. WARBURG, AUTUMN BY THE LAKE, GUDHAMMAR, SWEDEN, TRI-COlOUR CARBRo PRINT,

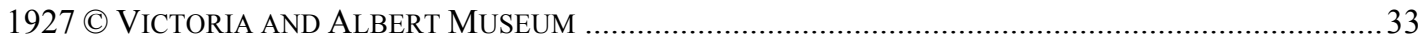

Figure 14. Agnes B. WARBURG, A BREEZy MORNING NEAR GotHENBURG, SWEDEN, PLATINUM PRint, CA.

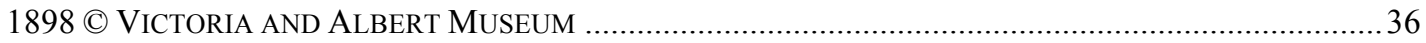

Figure 15. AgNes B. WARBURG, BUYING FLOWERS, PlatinUm PRINT, CA. 1899 C ViCTORIA AND ALBERT

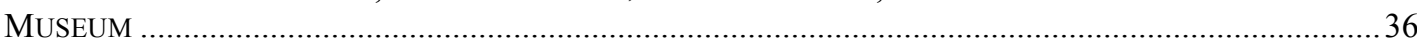

Figure 16. Agnes B. WARBURG, A CHERRY ORCHARD IN SPRING, SANGUINE-TINTED GUM PRINT, 1904 (C) VICTORIA AND ALBERT MUSEUM

Figure 17. Agnes B. Warburg, [UnTitled], Autochrome, CA. 1907, (C) Victoria ANd Albert Museum

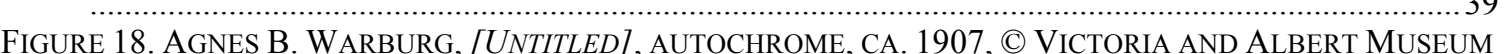

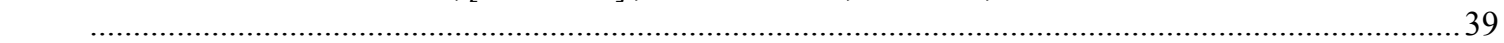

Figure 19. AGNES B. WARBURG, 5109.VENICE, 9 SEPT 1935, 10:20AM, 1/50@ @4.5, SUNSHINE, DUFAYCOLOR SLIDE, 1935, (C) VICTORIA AND ALBERT MUSEUM ....................................................... 42

Figure 20. Agnes B. WARBuRg, 5105. SWIMMING POOL, SS STRATHNAVER, 5 SEPT 1935, 1/50@ F3.5, 3P.M., CLOUDLESS, DUFAYCOLOR SLIDE, 1935, C VICTORIA AND ALBERT MUSEUM .....................................4 42

Figure 21. Agnes B. WARBurg, 5369. A T KYLE OF LOCHALSH, DufayColor Slide, 1937, (C) Victoria AND

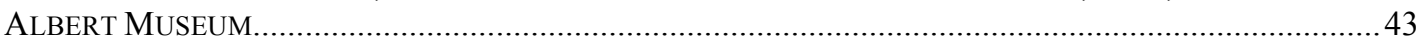

Figure 22. AgNes B. WARBURG, 5385. FEEDING HERRING GULLS, DUfAYCOLOR SLIDE, 1937 C Victoria

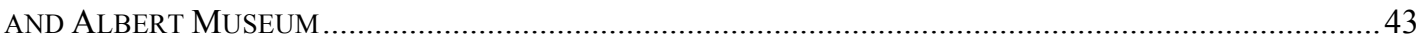




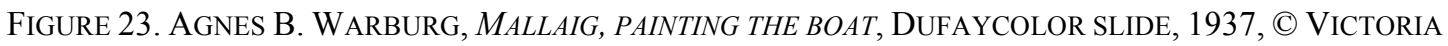

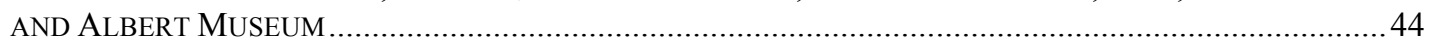

Figure 24. AgNes B. WARBURG, MALLAIG, PAINTING THE BOAT, TRI-COLOUR CARBRO PRINT, CA. 1937, C

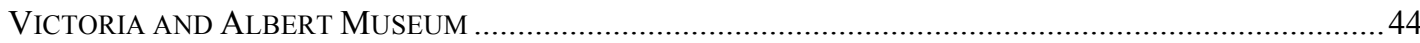

Figure 25. Agnes B. Warburg, COLORSNaP [RECTO AND VERSO], COLORSNAP PRINT, 1929 @ Victoria

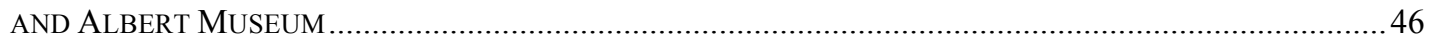

Figure 26. Agnes B. WARbURG, PEONIES, RAYDEX/OZOBROME PROCESS 1912 C Victoria AND ALBERT

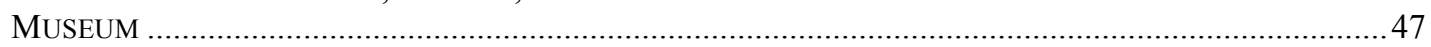

FiguRE 27. AGNES B. WARBURG, UNTITLED, INDIGO-TINTED CARBON PRINT, CA. 1904 C VICTORIA AND

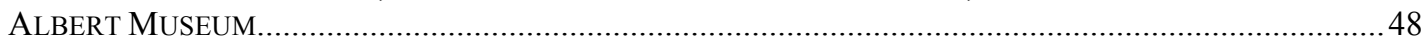

Figure 28. AgNes B. WARBURG, JOAN E.V. WARBURG, SANGUINE-TINTED GUM PRINT, CA. 1904 C VICTORIA

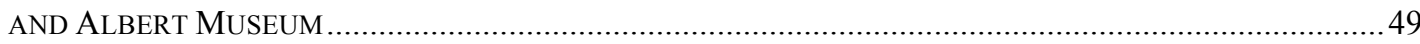

Figure 29. AgNes B. WARBURG, BOATS IN DUBROVNIK, TRI-COLOUR CARBRO PRINT FROM DUFAYCOLOR

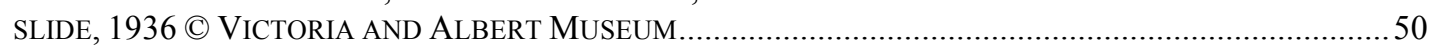

FigURE 30. TRI-COLOUR CARBRO STORYBOARD ASSEMBLED BY AGNES WARBURG AND USED DURING INSTRUCTIONAL WORKSHOP ON THE PROCESS, 1932 @ VICTORIA AND ALBERT MUSEUM ...................... 51

Figure 31. AgNes B. WARBURG, BOUGAINVILLEA, TRI-COLOUR CARBRO PROCESS, CA. 1935 @ VICTORIA

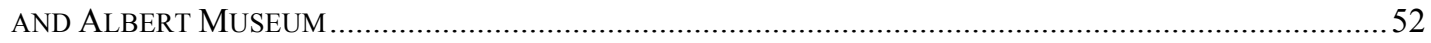

Figure 32. Agnes B. WARBURG, MY FIRST COLOUR PRINT, RAYDEX (OZOBROME) PROCESS, 1908, C)

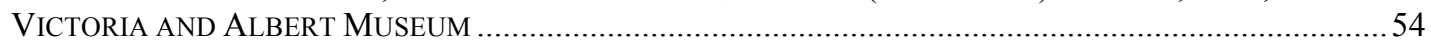

Figure 33. AgNes B. WARBURG, MORNING IN AFRICA, RAYDEX PRINT, CA. 1925 C VICTORIA AND ALBERT

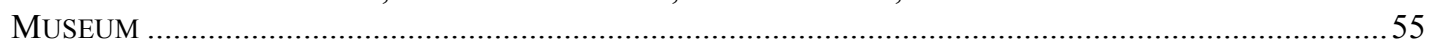

FiguRe 34. "WAR-TYPE," BRITISH JOURNAL OF PHOTOGRAPHY: COLOUR SUPPLEMENT 11, (NO. 134 OCTOBER

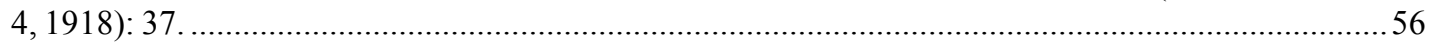




\section{Introduction}

Agnes Beatrice Warburg was a significant figure in British amateur photography circles who not only created and exhibited her photographs, but hosted lectures, frequently contributed to journals, ran clubs and actively supported the Royal Photographic Society (RPS) financially. Yet her interdisciplinary practice and dynamic connection to several aspects of photographic culture remain an under-researched chapter of photographic history. This is despite the fact that her photographs, and the amateur networks within which she worked, occupied an integral role in the development and history of early colour photography as a creative medium and intensive scientific practice. In this paper I have explored Warburg's aesthetic and technical uses of colour processes and how her photographs were circulated between 1907 and 1945. Through her extensive work with nine early colour processes, participation in salon exhibitions in the UK, and her deep involvement in the RPS Colour Group, I have identified Warburg as one of the most important early 'colour photographers' dedicated to interpreting the world around her in naturalistic colour through a uniquely pictorial lens. This study of Warburg's photographs and practice offers an additional way to understand early colour photographic history, and in doing so, exposes the roots of what is meant by 'colour photographer'.

The early history of photography (and its institutional history) can be traced back to Beaumont Newhall's 1937 exhibition Photography 1839-1937 and the subsequent editions of 'The History of Photography' he released afterward. 'This exhibition included hand-coloured daguerreotypes, tri-colour carbro prints, autochromes, and other additive and subtractive print processes. ${ }^{2}$ This is considered to be the first time that colour photographs were brought into public viewership within an institutional art space, in this case, the Museum of Modern Art in New York. However, the inclusion of colour photography in one institutional exhibit did not guarantee its public acceptance as an art

\footnotetext{
${ }^{1}$ Gil Pasternak, "Photographic Histories, Actualities, Potentialities: Amateur Photography as Photographic Historiography," Reconsidering Amateur Photography, accessed June 30, 2019, http://eitherand.org/ reconsideringamateur-photography/photographic-histories-actualities-potentialities-/

${ }^{2}$ Museum of Modern Art (MoMA), "Master Checklist," from the exhibition Photography 1839-1937, 119-120, accessed July 7, 2019, https://www.moma.org/documents/moma_master-checklist_387256.pdf
} 
form; it would take another forty years before MoMA curator John Szarkowski's acclaimed exhibition, William Eggleston's Guide in 1976 finally achieved this goal. ${ }^{3}$ With the exception of the autochrome, Newhall's historiography situated early twentieth century colour processes as either scientific or commercial, in effect negating them as relevant subjects of study in the history of photography that centred on art photography and pictorialism. This essay seeks to add a new dimension to Newhall's history of colour photography and to include Agnes Warburg as an innovative artist whose career demonstrates the critical role that amateur networks played in the technical and creative progression of early colour photography. Dedicated amateur photographers like Warburg welcomed wide audiences to their salon exhibitions, many of which contained colour photographs from the first moments in colour's history. They were deeply committed to all aspects of their craft and belonged to expansive internal and public networks specifically designed to promote the medium across its many uses. Amateur photography clubs like the RPS were hubs for discussion, collaboration and experimentation. Alongside their goals to partake in the growing community of colour experimentation, many, if not most, were also committed to creating fine art photographs encouraged by the deep pictorial origins of the Society.

Since the announcement of photography in 1839, amateur photographers made themselves privy to the technical and scientific conundrums faced by professionals in the field. The Royal Photographic Society was inaugurated in 1853 with the aim to discuss "the interchange of thought and experience amongst photographers." RPS spawned many other amateur clubs around the UK and beyond. These changeable networks and the photographers who engaged with them worked to see that photography gained the recognition they passionately felt it deserved, as scientific process and an expressive medium related to other forms of visual art. During the earliest parts of the

\footnotetext{
${ }^{3}$ Although there were other exhibitions of colour photography at MoMA during the intervening years including Eliot Porter, Birds in Colour: Flashlight Photographs in 1943 and Color Photography curated by Edward Steichen in 1950, art photography was still largely defined by straight documentary and photojournalism. Furthermore, the commercial connotations of colour photography were still very present, for the most part negating it from ongoing collection and display considerations.

${ }^{4}$ Michael Pritchard, "Our History," The Royal Photographic Society, accessed July 6, 2019, http://rps.org/about/history/history-of-the-rps.
} 
twentieth century art photography was only just beginning to make its way out of amateur club salons and into larger institutions. At the same time, the field of colour photography was expanding and its processes were growing rapidly to eventually include hundreds of complex photomechanical and chemical processes. However, due to its multiple roles in industry and commercially-based activities, colour photography had difficulty establishing a foothold in the art world. Further, early colour photography defied the artistic pedagogy put forward by photographers such as Alfred Stieglitz (1864-1946) and Henry Peach Robinson (1830-1907), insofar as the majority of colour processes at this time were not inherently photographic. Most colour processes shared ties to industrial printmaking, using inks, dyes, screens and elaborate processing techniques, and were most often executed by specialized tradesmen and technicians. These characteristics did not comply with the established conventions of photographic art production that favoured the presence of the artist's hand and other chemical and expressive qualities of photography. Commercial ties to advertising and print media established colour as a popular, mass-market tool, separate from monochrome art photography, that was only just beginning to appear in museums and galleries in the 1930s.

There is very limited reference of Warburg in published literature, and of the circles within which she worked. Perhaps the reason for this is twofold: limited physical access to her works in the RPS collection, and a paradigmatic approach to scholarship and research that has focused predominantly on the best-known highlights of the RPS collection. The RPS began collecting in 1920s with the mandate to acquire works made by all of its members. This resulted in a collection of approximately 270,000 photographs made by hundreds of photographers, spanning myriad processes and genres. Warburg's work can only be found in the RPS collection, it was not acquired by any other collecting institutions and has never appeared at auction. The RPS collection has changed hands three times in the last 50 years: from London to Bath in 1980, Bath to the Science and Media Museum in 2003, and finally to its current home at the V\&A in 2017. It has only 
been since its arrival at the V\&A that a finding aid has been made publicly accessible, via the V\&A study room website in $2018 .^{5}$

Alongside the physical challenges of access, the intellectual inaccessibility of the collection has also created a barrier for research into figures such as Warburg. Within the last few decades the field of photographic history has expanded to include subjects that lay outside the previously established masters of the medium, a group of artists in which women play a minor role. Investigation into professional and amateur figures like Warburg is in its early days and has been greatly bolstered by the recent increase in access to collections like the RPS, as well as a flurry of newly-published histories of photography. As a researcher, it is easy to enter a large photographic collection and be overwhelmed by its scale. The sheer magnitude of the RPS collection proved to be very challenging but with time, one can see innumerable opportunities to discover new artists and works that could potentially change how the history of photography has been told.

This thesis will be sectioned into four parts beginning with a review of current literature on the history of colour photography and amateur photography in the UK. Next I will introduce Agnes B. Warburg. There has yet to be a definitive biography of Warburg's life and collating materials to assemble one has been a central challenge in my research. Following that, I will discuss amateur culture and its definitions between 19001930 and how this related to professionals and other specialized users of photography. The bulk of this paper will be spent analyzing each of the processes she used between 1907 and 1945, their technical components and how she used them, predominantly in relation to her involvement in the RPS Colour Group. This focused approach to analysing the photographs and practice of Agnes Warburg will add to the history and understanding of this period of exciting photographic progress and its link with amateurism and notions of colour photography as fine art.

\footnotetext{
${ }^{5}$ The Victoria and Albert Museum, "The V\&A box list of glass-based photography in the Royal Photographic Society Collection," https://vanda-production-assets.s3.amazonaws.com/2018/05/02/14/25/01/465befda-76b2-4bf0-8935-

$7 \mathrm{c} 7 \mathrm{~d} 8 \mathrm{be} 7739 \mathrm{~d} / \mathrm{XRG} \% 20$.
} 


\section{Literature Review}

The purpose of this study is to bring together the integral, though relatively siloed histories of the colour photography in order to tell a broader and more integrated version of this dynamic and complex part of photographic history. A survey of current literature brings to light the scarcity of published material focusing on the early history of colour photography and its practitioners. Only since 2007 have scholars, including Lisa Hostetler, Pamela Roberts, and Sylvie Penichon, made significant contributions to colour photography's complex technological and institutional history. Their research succeeds in elucidating the collaborative and textured history of colour's experimenters as well as their litany of successes and failures that ultimately brought colour photography to be accepted by major collecting institutions.

Several scholars who have studied the early history of colour photography have addressed the autochrome and its impact. Pamela Roberts, former curator of the Royal Photographic Society Collection, published her book A Century of Colour Photography: From the Autochrome to the Digital Age in 2007. ${ }^{6}$ It included two essays related to Warburg's working period titled, "The Autochrome" and "Alternatives to the Autochrome, 1900-1930." The first of these essays, "The Autochrome" explores colour photography beyond its significance as a progression in imaging science by exploring it as a form of expression. The second, "Alternatives to the Autochrome" addresses the shortcomings of the autochrome process, providing an overview of both glass and paper processes that were emerging as a result. Roberts provides a brief biography on Agnes Warburg, discussing her involvement with the RPS and the British Journal of Photography along with the artistic relevance of her images. Roberts has written two other books that provide an understanding of the highlights of the most famous works in the RPS collection, both of which have been integral to my understanding of the Society. The first is a special issue publication titled, The Royal Photographic Society Collection,

\footnotetext{
${ }^{6}$ Pamela Roberts, "The Autochrome" and "Alternatives to the Autochrome 1900-1930," in A Century of Colour Photography: From the Autochrome to the Digital Age (London, England: Andre Deutsch Ltd. Carlton Publishing Group, 2007)
} 
published in 1994 to mark the 100-year anniversary of the RPS. ${ }^{7}$ Roberts's discussion on the history of their collecting practices was illuminating to the extent that it described how the collection came to fruition under the guidance of John Dudley Johnson in the early twentieth century, and described some of the treasures in the RPS collection. Roberts's other book, Photogenic: From the Collection of the Royal Photographic Society Collection, was published in 2001 and again, offers an overview of the recognizable names in the collection. ${ }^{8}$ In each of these books Warburg's name and a brief biographical sketch is offered, but none of her work is shown. The championing resource on Warburg has been curator and scholar Val Williams' Women Photographers: The Other Observers, 1900 to the Present published in $1986 .{ }^{9}$ Her book addresses Warburg in more detail, offering refreshing observations about Warburg's work and life. However, the energy of Warburg's pioneering approach to colour photography has not been sufficiently expressed by either Roberts or Williams. They lack detail and explanation regarding Warburg's elemental role in shaping the landscape of the RPS via the Colour Group, a network which I have argued contributed heavily to the development of colour photography, and as an innovative colour photographer in her own right.

While there were numerous technical publications written by scientists and engineers explaining the multifaceted nature of colour photographic technology, there was a dearth of published material addressing the work of colour photography's early practitioners. The few texts that were written leaned heavily toward the technical side of colour processes. Louis Walton Sipley, former Director of the American Museum of Photography published A Half Century of Colour in 1951. ${ }^{10}$ The book has four chapters offering a historical analysis of the first fifty years of colour photography. Similarly, Brian Coe, former curator of the Kodak Museum in Harrow, England wrote Colour Photography: The First Hundred Years 1840-1940 in 1978. ${ }^{11}$ Illustrated using objects

\footnotetext{
${ }^{7}$ Pam Roberts, "The Royal Photographic Society Collection: A Companion to the Photographic Journal," in The Photographic Journal Times 134, no. 10 (1994).

${ }^{8}$ Pam Roberts, Photogenic: From the Collection of the Royal Photographic Society (London, UK: Scriptum Editions, 2001).

${ }^{9}$ Val Williams, "Photography in Transition: An Overview (1840-1939)," in Women Photographers: The Other Observers, 1900-present (London: Virago, 1986), 11-24.

${ }^{10}$ Louis Walton Sipley, A Half Century of Color (New York, NY: MacMillan Co., 1951).

${ }^{11}$ Brian Coe, Colour Photography: The First Hundred Years 1840-1940 (London, England: Ash \& Grant, 1978).
} 
and photographs from the Kodak Museum collection, this book traces the history of early colour processes in use until 1940.

Jack Coote, author of The Illustrated History of Colour Photography, was a fellow of the Royal Photographic Society and researcher of colour photography. ${ }^{12}$ The book was published in 1993 and provides an overview of the social and technical history of colour photography until the 1990s. The book comprises fifteen chapters, each describing a different process and its uses. His book is the most comprehensive title on the history of colour, yet it was Sylvie Penichon, the head of Photograph Conservation at the Chicago Institute of Art, whose work held the most relevance to this project. Her book, Twentieth Century Colour Photographs: Identification and Care is a definitive resource for understanding the characteristics and components of the most historically and commercially significant colour processes of the 20th century. ${ }^{13}$ The book's seven chapters offer a user-friendly guide to materials and their history, methods of identification, and common kinds of deterioration. This book was by far the best resource to understand and describe the processes used by Warburg during this time period and their relevance within the larger history of colour.

In 1993, Henry Wilhelm and Carol Bower self-published The Permanence and Care of Color Photographs: Traditional and Digital Color Prints, Color Negatives, Slides and Motion Pictures, a massive tome that concentrates on preservation issues related to commercially manufactured colour photographic materials in the latter half of the twentieth century. ${ }^{14}$ However, Wilhelm and Bower also touch on colour photographic processes and the track the earliest efforts of major American museums such as MoMA and the Art Institute of Chicago to collect colour photography, an activity that was only starting to gain momentum by this time. A broader investigation into early colour photography's history was undertaken by Lisa Hostetler, Curator of Photographs at the George Eastman Museum, through a survey exhibition at the Milwaukee Art Museum in

\footnotetext{
12 Jack H. Coote, The Illustrated History of Colour Photography (Surrey, England: Fountain Press Limited, 1993).

${ }^{13}$ Sylvie Penichon, Twentieth Century Colour Photographs: Identification and Care (Los Angeles, CA: Getty Conservation Institute, 2013).

${ }^{14}$ Henry Wilhelm and Carol Bower, The Care of Color Photographs: Traditional and Digital Color Prints, Color Negatives, Slides and Motion Pictures (self-pub., Kingsport, TN: Wilhelm Imaging Research, 1993).
} 
2013 titled, "Color Rush: 75 Years of Color Photography in America." ${ }^{15}$ Hostetler's catalogue essay, "Real Color", traces the history of colour photography beginning with the Autochrome in 1907 and culminating in 1980, at which time color photography had been widely accepted within the fine art world. It seeks to acknowledge the developments in color photography through time, focusing on the applications of color imagery at the time of their making, rather than the technology that underlaid it. For example, during the period when Warburg was producing her work, Hostetler's chapter titled "Consuming Color" focuses on the nature of colour imagery as a widely used medium for commercial advertising and editorial content in the newly created picture magazines such as Life, Look and The Saturday Evening Post.

This literature review shows a gap in research on colour photography between 1907 and 1935 and a need for broader interpretations and deeper investigations into this part of the RPS collection. This study contributes another facet to our understanding of this type of photography and the culture to which it belonged.

\footnotetext{
${ }^{15}$ Lisa Hostetler, "Real Color," in Color Rush: 75 Years of Color Photography in America (New York, NY: Aperture and the Milwaukee Art Museum, 2013), 20-27.
} 


\section{Chapter 1: History of Colour until 1907}

This history not been present in much of the scholarship surrounding the broader history of photography. In the context of this paper this section establishes a basis for a clearer understanding of the degree of experimentation that preceded Warburg's colour experiments that began in the late 1890s. By contrast, analysis of this period enables us to better perceive the concentrated the level of experimentation that occurred after the invention to the autochrome. By gathering the histories of colour until 1907 this section will illustrate the relatively few ideas and processes that had informed Warburg's work. Furthermore, this history indicates that scientists were the sole contributors to the history of colour photography prior to 1907. Consideration of Warburg's career with knowledge of the factors that stemmed from this history and context allows us to better understand the magnitude of her contributions as an amateur photographer, who I argue had a distinct effect on how the public came to understand and use colour photographic techniques.

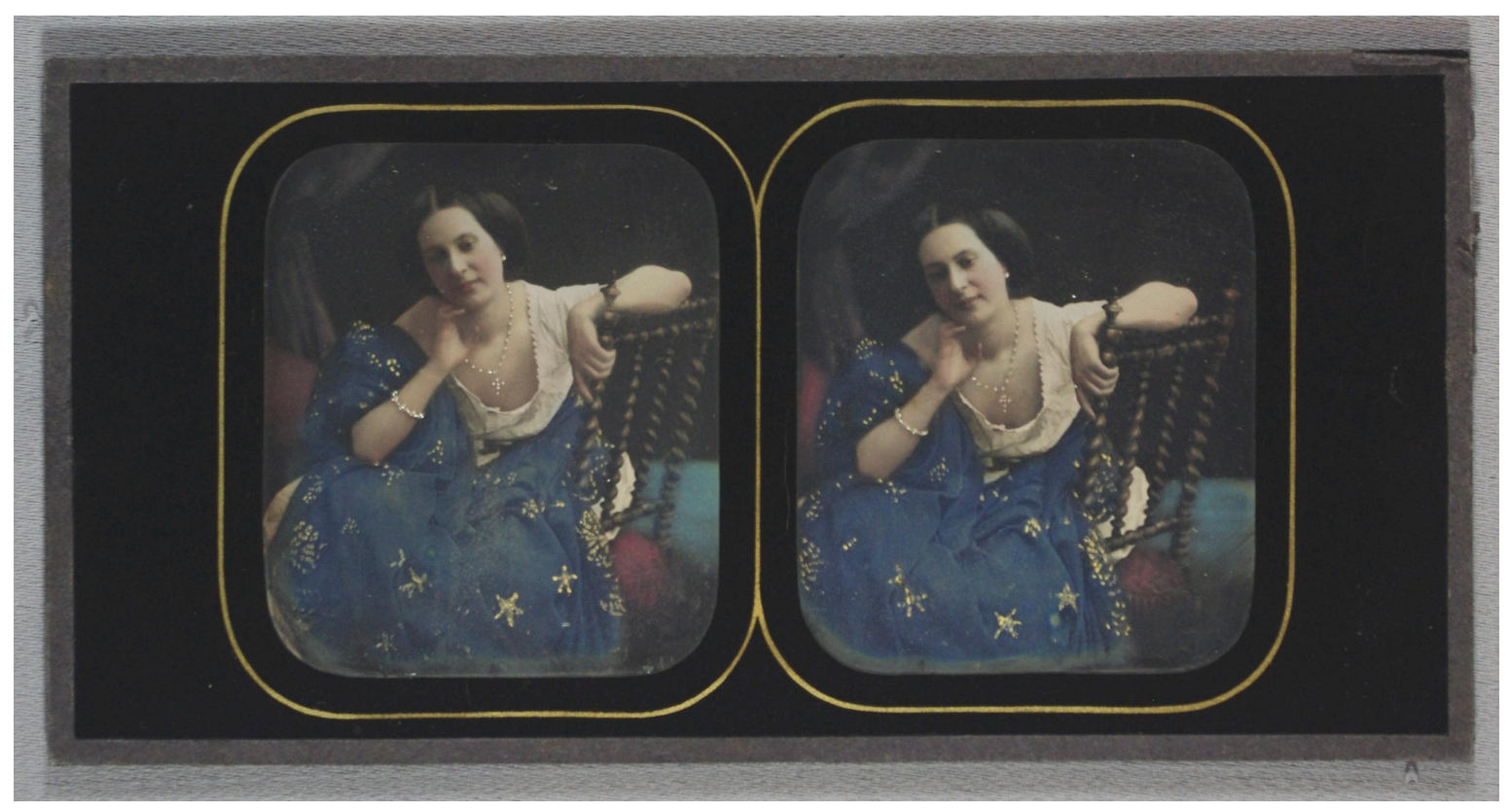

Figure 1. Paul Emil Chappuis, [Artists model], hand-tinted daguerreotype, ca. 1861 (C Victoria and Albert Museum

In 1839 Louis-Jacques Mandé Daguerre and William Henry Fox Talbot announced their respective inventions of photography almost simultaneously. The calotype and the Daguerreotype differed in many ways, but they shared a lack of colour. 
Initially photography was revered for its precision in replicating its subject, but it was criticized for its inability to capture colour, a fundamental component of nature itself. As the challenge to find a means to photographically capture colour began, it became common practice amongst Daguerreotypists to hand-colour images using techniques that echoed miniature portrait painting. Hand colouring was not as common amongst calotypists because the resolution of the image was poor and the paper substrate too fragile.

\section{The Study of Light and Colour}

A critical component to creating colour photographs was to understand how the human eye perceived and understood the nature of light. In 1666, Isaac Newton was able to deduce that white light could be divided into three separate colours, red, green and blue, when broken up by a prism. From there, he was able to articulate that any colour could be created using a combination of these three 'primary' colours under the division of white light through a prism. Newton suggested that coloured light was made up of tiny particles, but English scientist Thomas Young (1773-1829) later disproved this. Building upon Newton's research, Young put forward the concept that light ran in waves: red light was the longest wave, and violet was the shortest. This theory would become critical to later developments in photographic emulsions, but his central contributions were his theories of trichromatic colour vision: how the brain creates colour. ${ }^{16}$ German physicist Hermann von Helmholtz (1824-1894) theorized that the cone cells in the retina of the eye each hold a different sensitivity to the wavelengths carried by each of the primary colours. For example, to our eye, the colour red is created by the action of a cone cell detecting the corresponding 'red' wavelength and then sending that information through nerves to the brain, where the sensation of red is received and created. Louis Walton Sipley rightly stated, "colour is a sensation and the matching of colour is a psychological process." $" 17$

\footnotetext{
${ }^{16}$ Penichon, Twentieth Century Colour Photographs, 10.

${ }^{17}$ Walton Sipley, A Half Century of Color, 2.
} 


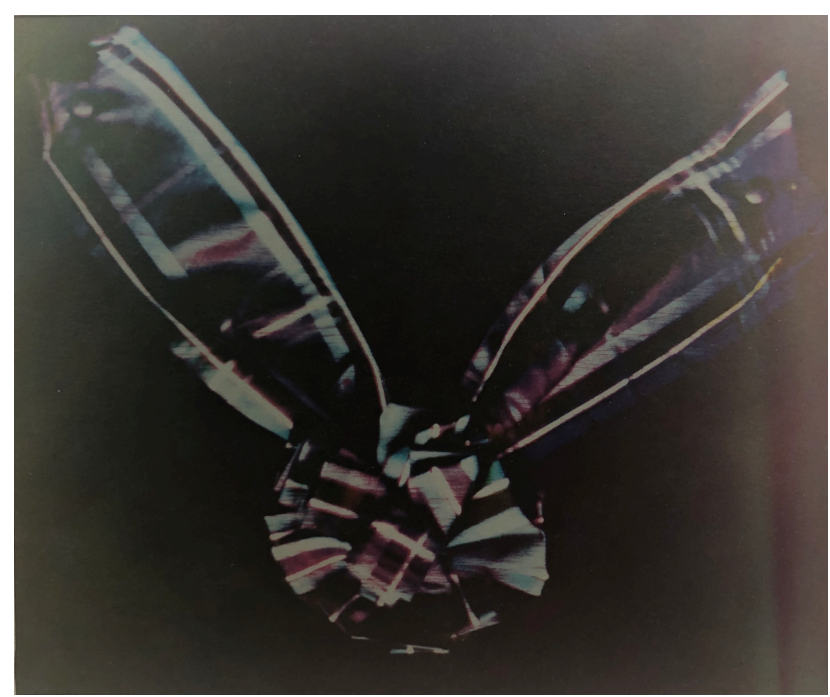

Figure 2. D.A. Spencer, Tartan Ribbon, Vivex process, printed 1933 using original James Clerk Maxwell positive transparencies created in 1861 (C) Victoria and Albert Museum
James Clerk Maxwell famously

tested the Young-Helmholz theory

before the Royal Institution of London

in 1861 . When considering this

moment, it must be noted that to

Maxwell, the experiment was an

incident in the study of colourimetry

and not a step in the development of

colour photographic process. ${ }^{18}$

Maxwell was not interested in

photography, but the physics of colour.

Nevertheless, in collaboration with

photographer Thomas Sutton (1819-1875) he sought out to prove that "any tint may be imitated by mixing red, blue and green alone. ${ }^{119} \mathrm{He}$ commissioned Sutton to produce three black and white negatives, each to be photographed through red, green and blue filters (Figure 2). These three negatives would become known as 'separation negatives'. They were then turned into positives and projected in superimposition through their respective coloured filter.

This was the first additive colour synthesis method, constituting the addition of three beams of red, green and blue coloured light (Figure 3). "When only all three colours are combined, white is produced; when only two colours are combined, the

Figure 3. Illustration demonstrating additive colour synthesis onto an image plane. When the three primary colours are projected, a spectrum of colours is created: addition of all three colours results in white; a mixture of green and blue produces cyan; blue and green produces magenta; red and green produces yellow.

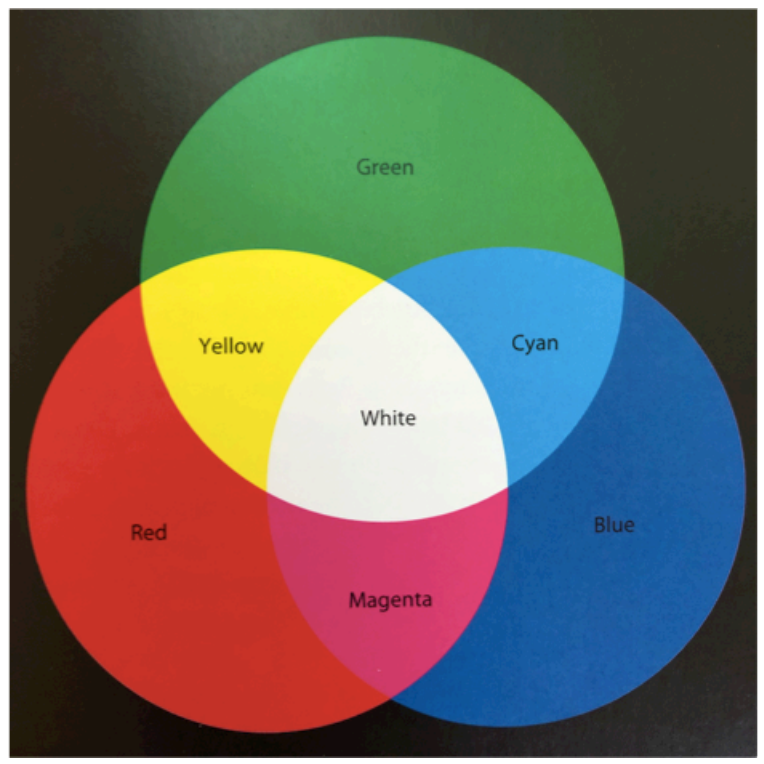

\footnotetext{
${ }^{18}$ Ibid., 6.

${ }^{19}$ Penichon, Twentieth Century Colour Photographs, 10.
} 
complementary colours yellow (red and green), magenta (blue and red), and cyan (green and blue) result." ${ }^{20}$ The resulting projection was a full colour image and as if by accident, the path to colour photography was found.

\section{Initial Attempts at Direct Colour}

"Scientists concentrated their efforts on searching for a substance able to assume the colour of any light that fell on it, like a chameleon, and would produce direct colour photographs. ${ }^{21}$

Simulating the behaviour of our eye was simple enough to mechanically produce via hand colouring and pigment printing, but to replicate it photographically posed a much larger challenge. The task was to create a photographic emulsion and technology that could behave as if it were a cone receptor in the human eye, synthesizing waves to present colour on a physical plane such as paper, glass, metal or film. Perhaps relating to the complexity of this undertaking and the efficiency of hand-colouring techniques, the field of research into a solution to the colour problem was dormant for the first decade of photography's existence. That was until 1850 when a handful of researchers emerged who advocated that direct colour photography was possible. The first person to claim any success in reproducing colours directly onto paper was Frederick William Herschel in 1840. Unfortunately, like many that were to follow, he was unable to fix the images, which faded quickly. Within the decade, Alexandre Edmond Bequerel (1820-1891), Reverend Levi H. Hill (1816-1765) and Claude Félix Abel Niépce de Saint-Victor (18051870) stated their triumph over colour through claims they had directly produced a colour image onto a metal plate.

Bequerel began his broad exploration into the chemical effects of light in 1848 . His research enabled him to electrochemically capture the light spectrum directly onto a plate without any type of development - the longer the exposure time was, the brighter the colours would be. However, he was unable to fix the image, as it would vanish in any amount of daylight, leading to an acceptance of the conclusion that his contributions were

\footnotetext{
${ }^{20}$ Ibid., 13.

${ }^{21}$ Ibid., 5.
} 
"only of a scientific interest." 22 In 1850 Reverend Levi Hill boldly told the public that he had found a way to produce a colour daguerreotype using only the sun. Alongside statements that the process would be fairly priced, a frenzy of excitement ensued amongst commercial users of the daguerreotype. Unfortunately, by the time the process was released six years later, the public was no longer interested, because daguerreotypes had been replaced by the wet collodion process in combination with reproducible albumen prints as the most widely used photographic technology. As a result, Hill's process went down in history as a fraud. That remained the story until 1980, when Joseph Boudreau at Panier College of Art in Hamden, Connecticut carried out the 'Hillotype' method using Hill's notes and was able to deduce that he was not in fact fraudulent in his claims of success. ${ }^{23}$ The last attempt at direct colour photography in the 1850 s was made by Niépce de Saint-Victor using a process he called heliochromy. To create an image, he returned to Becquerel's experiments using electrochemistry and found a way to improve stability, exposure time and colour accuracy of the image. But the permanence of the image was still too weak too be used commercially and it was added to the long list of 'failed' early colour experiments.

\section{The Solutions}

In 1862 at the age of 25, Louis Ducos du Hauron (1837-1920) successfully produced the first stable colour images on paper using Maxwell's additive theory. He presented this process to the Academy of Sciences in Paris, but it was rejected and he returned to his experiments. In addition to the process, he proposed a design for a camera that would make three separation negatives through one exposure using angled transparent mirrors which "in design and theory was the forerunner of modern one-shot cameras. ${ }^{, 24}$ In 1868 his trials with additive processes led to his discovery of a tricolor process made through the subtractive synthesis method. The three subtractive colours are yellow, cyan and magenta and are the additive colour synthesis complements. Each of the subtractive colours absorbs or subtracts the complementary colour's light: blue, green or

\footnotetext{
${ }^{22}$ Ibid., 8 .

${ }^{23}$ Ibid., 9.

${ }^{24}$ Walton Sipley, A Half Century of Color, 9.
} 
red, respectively. "By subtracting one of the three primary additive colours from white light, the other two remain to produce a specific colour.

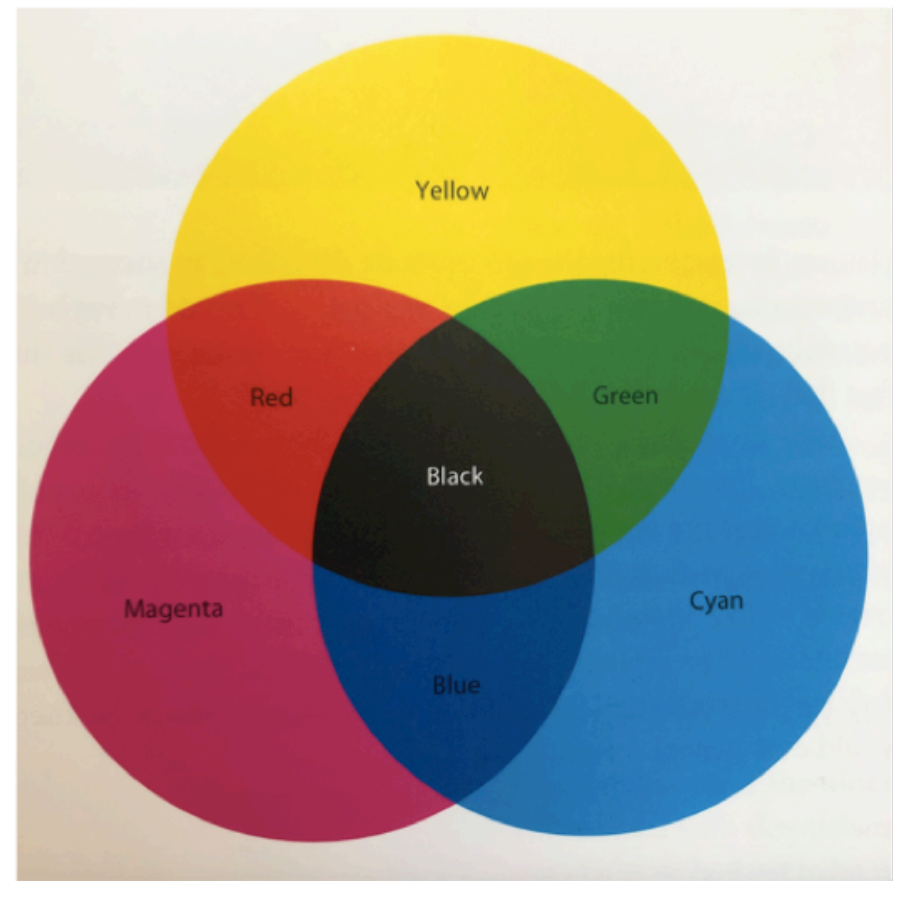

Figure 4. Illustration demonstrating subtractive colour synthesis created through the absorption of the three primary colours from white light. When the subtractive colours, cyan, yellow and magenta are taken from a white light source the following colours are created: subtraction of all three colours results in black; a mixture of cyan and yellow produces green; cyan and magenta produces blue; magenta and yellow produces red.

Ducos du Hauron patented this tricolor carbon process and sent three photographs to the Société française de photographie with a letter that described, "how to make the sun paint with all the colours presented to it." ${ }^{, 25}$ At this time, it was indicated to Ducos du Hauron that another scientist, Charles Cros (1842-1888) was simultaneously working on the same process. Together, these two men had uncovered the subtractive tricolor method of producing colour, the basis of all commercial colour photographic processes to come (Figure 4). Almost immediately, this indirect process received pushback from the public, who felt it was not inherently photographic. Critics felt it necessary to return to the pursuit of direct colour as attempted by Bequerel and Niepce, a problem that would take another forty years to solve.

The invention of silver gelatin emulsions and the freedom it afforded to photographers and experimenters enabled great advancements in colour research. In 1873, Hermann Wilhelm Vogel (1834-1898) found that through the addition of dyes to

\footnotetext{
${ }^{25}$ Ibid., 14.
} 
silver emulsions it was possible to make an emulsion sensitive to certain parts of the colour spectrum. His experiments were the beginnings of recognizing orthochromatic and panchromatic emulsions. ${ }^{26}$ Orthochromatic emulsions were those receptive to only blue and green wavelengths, and panchromatic were those sensitive to all (the addition of red) waves in the visible spectrum. French physics professor Gabriel Lippmann (1845-1921) recognized that people were becoming increasingly skeptical about the indirect colour methods put forward by Ducos du Hauron and Charles Cros, and was able to create a process that required only an emulsion and light. However, this process was incredibly complex, making it inaccessible to the commercial market. Aptly named the Lippmann process, he created unique colour images on glass plates using interference colour photography or interferential photography. ${ }^{27}$ Through intense application of mathematics, optics and chemistry he was able to record standing waves onto a thick glass plate coated with a thin layer of silver halides and gelatin in $1891 .^{28}$ Lippmann was awarded the Nobel Prize in Physics for his invention of this process in 1908. Among the many people who were fascinated by this process were Auguste and Louis Lumière. ${ }^{29}$ As manufacturers of the then-fastest silver gelatin dry plates, the Lumière brothers worked for many years to better Lippmann's process by improving light sensitivity. However, they abandoned this project in favour of improving the indirect methods for colour photography. By this period, new additive screen processes had become available, including the McDonough and Joly plates, but these processes produced poor colour quality, and were subject to the scrutiny of critics who continued to disapprove of indirect colour methods. Prior to the invention of their autochrome plates, the Lumière brothers had developed a transparency process that combined methods using separation negatives and carbon printing, called ALL Chroma. ${ }^{30}$ Being savvy businessmen, they realized that the process was too complex and they continued their pursuit to create a process that would be useable by all types of photographers. ${ }^{31}$

\footnotetext{
${ }^{26}$ Walton Sipley, A Half Century of Color, 11.

${ }^{27}$ Hans I. Bjelkhagen, "Lippmann Photography: its history and recent development," 1, Holography Forum, accessed July 7, 2019, https://www.holographyforum.org/data/lippmann/Bjelkhagen-Lippmann_Photography.pdf

${ }^{28}$ Bjelkhagen, "Lippmann Photography: its history and recent development," 1.

${ }^{29}$ Ibid., 18.

${ }^{30}$ Lavedrine and Gandolfo, The Lumière Autochrome, 69.

${ }^{31}$ Ibid., 69.
} 
Meanwhile, growth in colour advertising using the graphic arts, sparked by early additive processes, was evolving. In 1881, Frederic Ives patented the halftone printing process that revolutionized how images could be replicated in mass print media. Ives's ideas would be manifested in colour by William Kurtz, the "Engraver and Printer of Boston," who developed a technique to produce halftone three-colour prints using a printing press. These manufacturing techniques would revolutionize how the public was able to engage with colour imagery in books, magazines, newspapers and on billboards. Simultaneously, this contributed to colour imagery's reputation as a purely mechanical, industrial medium, separate from direct photographic methods that could produce art photographs. According to Walton Sipley, the 1890s were more 'art minded' than 'photography conscious' and printed reproductions of paintings and watercolours were in far greater demand than 'direct from nature pictures. ${ }^{32}$ This changed in the early twentieth century, and in 1904 the Colorplate Engraving Company in New York City began reproducing colour plates. This included a group of autochromes created by Alfred Stieglitz, Edward Steichen and other members of the Photo Secession, a group of influential American photographers who worked to have photography accepted as a fine art in the early 1900 s.

This short, textured history of colour photography until 1907 provides context in which to consider the continued progress of the medium. The Lumière brothers' invention of the autochrome in 1907 ended photography's arduous journey towards establishing a way to replicate the world in natural colour, but its shortcomings were quick to reveal themselves. The need to address these faults opened up a new realm of possibilities for both scientists and photographers, such as Warburg. It introduced them to a new set of challenges aimed at making colour photography more accessible and affordable - better quality and more functional. It would be another thirty years until these criteria were met. Kodak's release of Kodachrome and chromogenic colour coupler technology in 1935 provided the breakthrough technology that would be used to produce most twentieth century colour photographs. This marked the beginning of a new era in colour photography that was driven by manufacturers, essentially eliminating the craft

\footnotetext{
${ }^{32}$ Walton Sipley, A Half Century of Color, 32.
} 
developed by Warburg and her colleagues. Kodak's new colour film products offered such a significant improvement in the rendition of naturalistic colour that it is often assumed that the development of colour photography miraculously leaped from the autochrome to Kodachrome. This however, has left the intervening years between 1908 to 1935 , a time of enormous colour experimentation and development by individual photographers as well the growing manufacturers, still largely unexplored. 


\section{Chapter 2: Agnes B. Warburg (1872-1953)}

Agnes Beatrice Warburg was the third of five children born in London, England in 1872. A distant cousin of the prominent American Warburg banking brothers, her Swedish father Frederic Warburg (1832-1899) was also a highly successful businessman who founded the first London City underground in $1889 .{ }^{33}$ It was referred to as the London Central line, or the two-penny rail, because it only cost two pence to ride from one end of the line to the other. As a result of their father's fortune, the Warburg children had a very privileged upbringing; they did not attend regular school, instead they were educated by a governess in their large Victorian home at 8 Porchester Terrace in Kensington, London. ${ }^{34}$ Their parents, Frederic and Emma, were remembered as stern parents, "feared more than loved [by their] children." 35 Nonetheless, their father's success afforded them many things, not the least of which was a life of leisure, and in the case of Agnes and John Cimon, the eldest brother, the pursuit of photography.

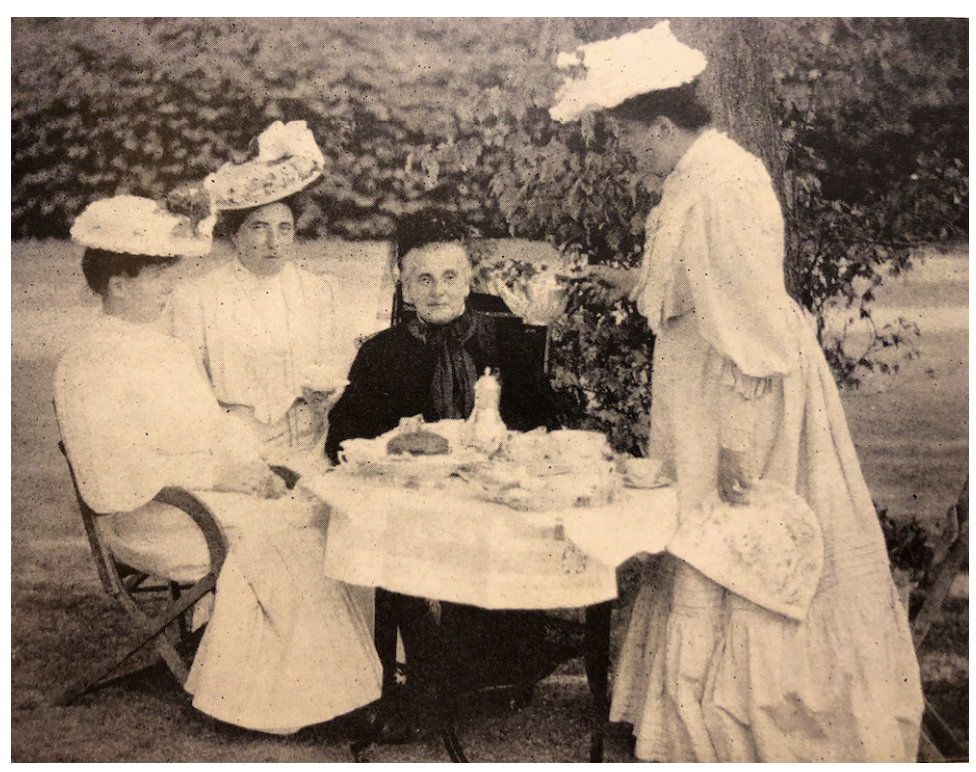

Figure 5. (Left to right) Agnes Warburg, Lily Warburg (sister), Emma Warburg (mother), Violet Sichel (wife to John Cimon Warburg)

Agnes Warburg began making photographs in the mid-1880s, under the guidance of her elder brother John Cimon, who was at that point an established member of both the RPS and the Linked Ring Brotherhood. The Linked Ring was a breakaway group of photographers from the RPS founded by Henry Peach Robinson to exclusively support the artistic merits of photography. Because of his involvement in these clubs, Agnes would have spent much of her early life as a photographer on the fringes of the

\footnotetext{
${ }^{33}$ Warburg, An Occupation for Gentlemen, 18.

${ }^{34}$ Naomi Rosenblum, "Biographies," in A History of Women Photographers (New York, NY: Abbeville Press Publishing Group, 1994), 324.

${ }^{35}$ Warburg, An Occupation for Gentlemen, 18.
} 


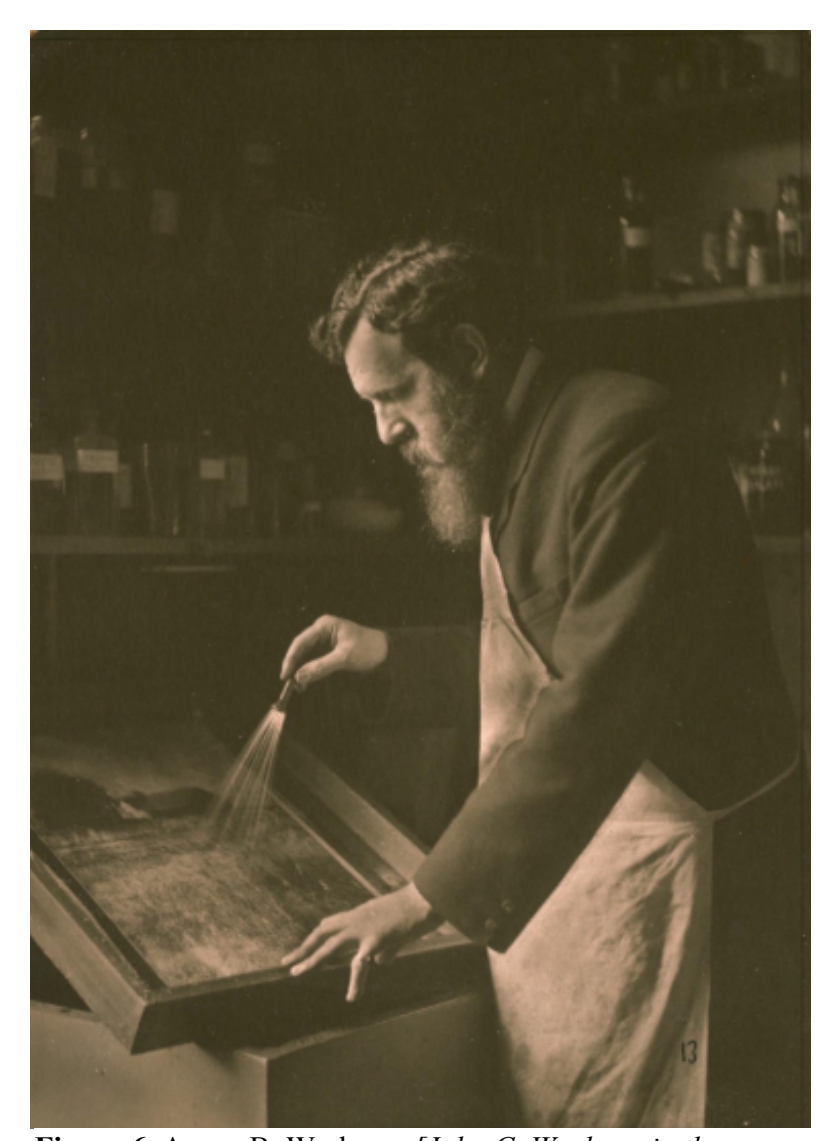

Figure 6. Agnes B. Warburg, [John C. Warburg in the darkroom], carbon print, ca. 1900 (C) Victoria and Albert Museum highest levels of photographic discussion, though at the time not permitted to participate in the discussions themselves. It is said that she and her brother had a complex relationship; he was reclusive, cynical, and suffered from chronic asthma that brought him to his untimely death in 1931 at age $64 .{ }^{36}$ John's son Frederic remembers the hours his father would spend in his darkroom, "used for development, printing, and enlargement of photographic plates and other mysteries of his art. From this room at all times emanated a powerful smell of chemicals. ${ }^{37}$ No doubt, this room was also the place where John Cimon introduced his sister Agnes to the mysteries of handmade photographic printing processes such as Gum Arabic, Carbon and Platinum which undoubtedly sparked her interest in photography and early colour processes.

Warburg's practice began with monochrome processes such as platinum and carbon printing and was shaped by the pictorialist influences of groups like the RPS and Linked Ring. She photographed gardens, still lifes, and close family members-all subjects that she would continue to photograph over the course of her nearly 60-year career. Her black and white works were exhibited widely in England including in many amateur contests and salons, the RPS annual exhibitions, and the Linked Ring salon. ${ }^{38}$ Her body of work indicates that she was captivated by colour from her earliest involvement in photography. Her ensuing experiments with both plate and print colour

\footnotetext{
${ }^{36}$ Ibid., 129.

${ }^{37}$ Ibid., 22.

${ }^{38}$ Rosenblum, "Biographies," 324.
} 
begin in 1907 with the autochrome and quickly grew to include three-colour pigment and additive screen processes. In all cases, she brought her commitment to the pictorial to her work. Her colleague Frank Newens recalled, "[s]o many of the early colour workers were concerned almost wholly with the technical aspects of making colour prints, few possessed the flare [sic] for applying pictorial and artistic principles as Miss Warburg did." ${ }^{39}$ Val Williams, author of Women Photographers: The Other Observers, 1900 to the Present remarks that Warburg's approach to pictorialism was both within and outside the bounds of the romantic and domestic themes presented in pictorialist photographs by her female contemporaries. Warburg aimed to capture human intervention in her pictorial scenes. "When she photographs the sea, there is often a boat dominating the picture, a river is traversed by a stone bridge, a view across the hills is bisected by an iron fence." $" 40$ She had a love for travel and photographed wherever she went: Morocco, Denmark, Portugal, Scotland, Sweden, Greece, Yugoslavia, South Africa, her camera always capturing similar domestic scenes and landscapes. However, as time, photographic technology and artistic practices in photography evolved, there were some recognizable changes made to her working method and style.
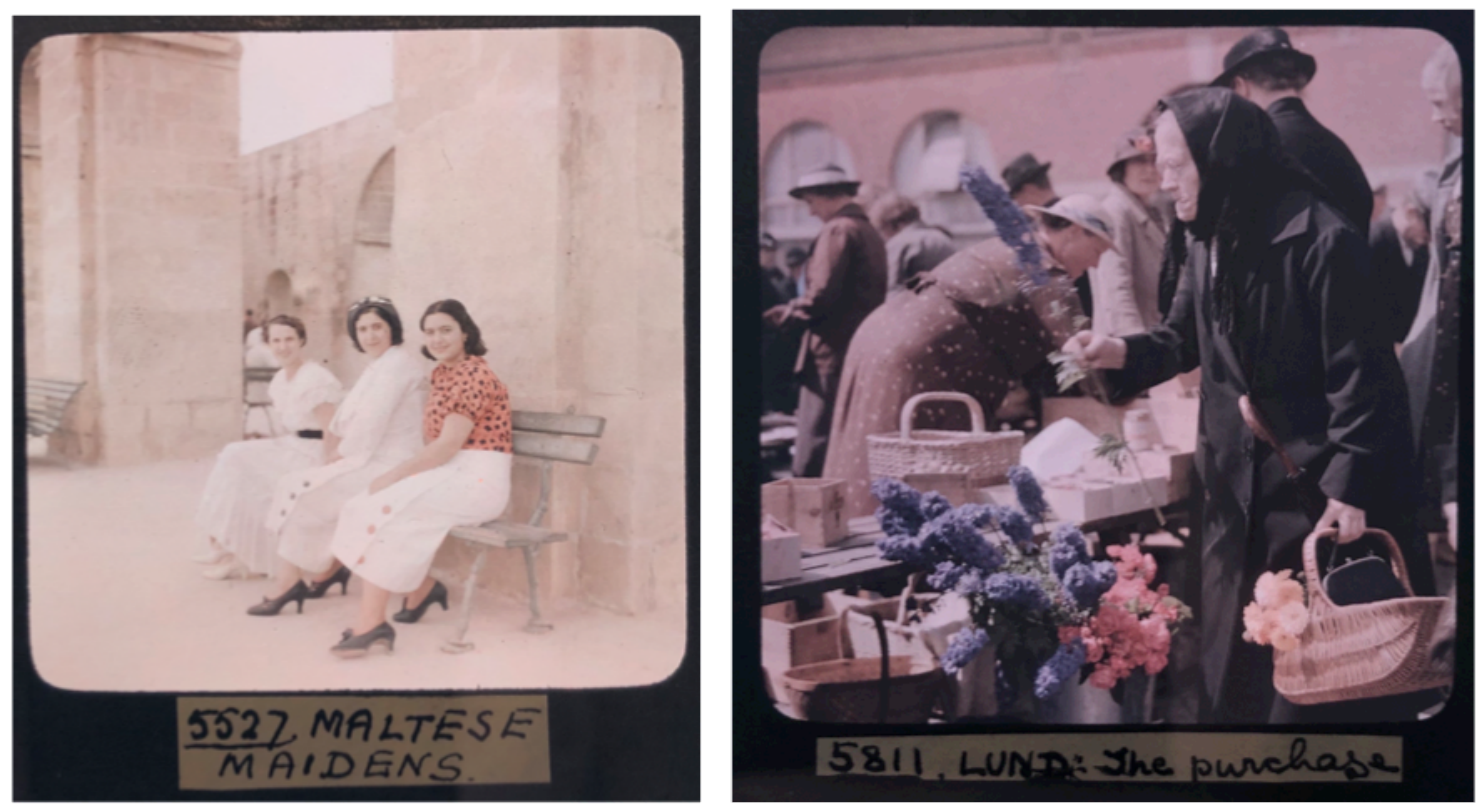

Figure 7. (Above left) Agnes B. Warburg, 5527. Maltese Maidens, Dufaycolor, 1938 (C Victoria and Albert Museum

Figure 8. (Above right) Agnes B. Warburg, 5311. Lund: The purchase, Dufaycolor, 1938 (C) Victoria and Albert Museum

\footnotetext{
${ }^{39}$ Frank R. Newens, “Obituary: Agnes B. Warburg (Fellow),” Royal Photographic Society Journal 93, no.3 (March 1953): 111.

${ }^{40}$ Williams, "Photography in Transition: An Overview (1840-1939)," 20-21.
} 
By the 1930s, when Warburg began using slide materials, photography was transitioning away from the mannered and timeless images of pictorialism to black and white "straight photography". This shift was driven by the ability of photographers (and the materials they employed) to capture some fleeting moment in everyday life that liberated both the content and practice of image making. The emergence of Dufaycolor in 1935 provided Warburg with an easy alternative to printmaking that offered faster shutter speeds, greater ease of production and higher resolution, enabling her to photograph the "real world" in a way that had not been possible with the technology used to create her earlier colour prints. It could be argued that her work with slides is emblematic of Warburg's transition from the romantic inclinations of the Pictorialists to an emerging "real world" documentary style that was growing out of the picture magazines. This can clearly be seen in the two Dufaycolor photographs above. Both made later in her career, Maltese Maidens (Figure 7) is a posed portrait, and Lund: the purchase (Figure 8) captures a candid moment.

The quiet nature of Warburg's photographs suggests she may have been a somewhat shy and passive observer, but these qualities did not necessarily apply to her personality. Warburg was a very eccentric woman-known amongst her colleagues for her generosity, dry sense of humour and remarkable wit. She did not shy away from sharing her sense of humour publicly, often inserting it into British Journal of Photography (BJP) and RPS journal articles. In one instance where a group of editors provided some ill advice to a struggling photographer, she sarcastically plays up the notion that women are of lesser intelligence and begins a retort with, "Gentlemen, In the BJP of July 15 you advise a correspondent, who is in trouble with his tri-colour carbro..." and then proceeds to describe and solve the issue exactly. She closes her letter saying, "An empirical dabbler like myself only knows enough to make up a fresh batch of acid bath when a specially important print is in hand, and this may be (for all I know) only a burn-offering to propitiate the gods." 41 Anyone who read the letter could surmise that she was not a dabbler-she was an expert attempting to outshine her male colleagues with both her

${ }^{41}$ Agnes Warburg, "Three-Colour Carbro: To the Editors," The British Journal of Photography 74, no. 3507 (July 1927): 439. 
knowledge and her wit. Her letter is indicative of the climate of exchange that is embedded in the history of colour photography during this time period. It emphasizes that amateur photographers were not bystanders to colour photography's progression, a notion that until recently has been largely unexplored, instead privileging the scientists working in at large commercial outfits such as Kodak or Lumière. Warburg's display of character, knowledge and participation establishes her fortitude and commitment to influencing the landscape of colour photography in the same way that commercial photography companies aspired to: to make it more accessible and affordable.

Over the course of her life, her work was shown widely around Britain and beyond. Stamps on the backs of prints show that her work was exhibited overseas in other amateur photography exhibitions including the International Photographic Exhibition in Lucknow, India; The International Circle of Pictorial Photographers Annual Exhibition; Liverpool, UK (1927); The Dublin Salon of Photography; The Camera Club, New York (1929); The Chicago Camera Club (1929); The Smithsonian Institution National Museum (Washington), Section of Photography (n.d); The Photo Pictorialists of Milwaukee exhibition at the Milwaukee Art Institute (1929); the Croydon Camera Club exhibition and more. Despite their wide travel, her work was never used or exhibited outside of pictorial displays.

\section{Warburg's professional activities} were closely intertwined with her social life. She had many friends and

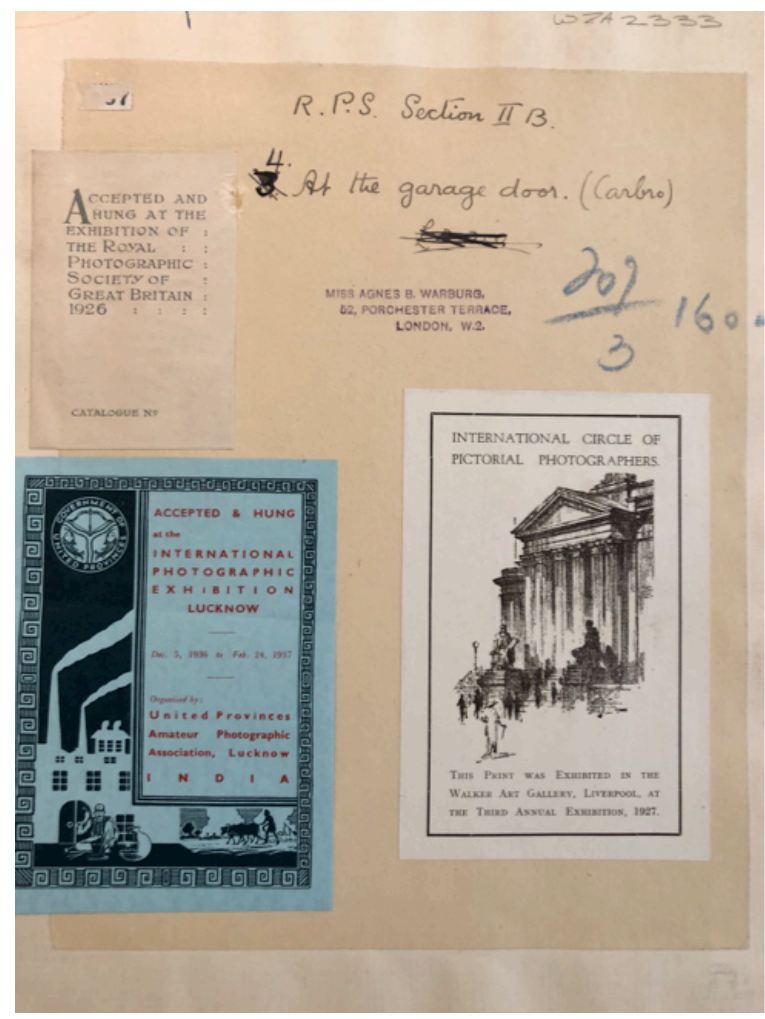

Figure 9. Agnes B. Warburg, At the garage door, verso, tri-colour carbro print, 1929. Stamps indicating international exchange locations of print: The Royal Photographic Society, 1926; The International Photographic Exhibition, 1927, Lucknow, India; International Circle of Pictorial Photographers, 1927, Liverpool (C) Victoria and Albert Museum 
influences within the RPS, the most important of which was Violet K. Blaiklock (18791961). She and Warburg started the RPS Colour Group together in 1927 and they remained friends until Warburg's death. They were close collaborators, often photographing very similar domestic and garden scenes. It can be suggested that some of Warburg's knowledge of photomechanical processes is likely a result of their friendship. In order to pursue colour photography at this time, one required both the money to fund the work and the time it took to succeed with these onerous processes. For many colour photographers such as Violet Blaiklock or Madame Yevonde, whose work is also held in the RPS collection, it was necessary to have parallel career as a commercial artist. Yevonde and Blaiklock were both commissioned to produce colour photography for magazines and/or advertising campaigns. This work would have provided them access and insight into the industrial production of colour by highly skilled technicians who created the colour separations and proof prints leading up to the mass-produced print products such as magazines and posters. Warburg, on the other hand, through her combination of wealth, persistence and patience, pursued colour printing in the same manner she had created her other photographs using other processes. Her colour prints and slides were not an intermediate step required in mass-produced reproductions but were meant to be the final, handcrafted product and viewed as unique artworks. In a time when colour photographs were either a garishly commercialized form of visual communication or a novel technology used by a few fine artists, Warburg appears to have been one of the very few who embraced the idea that all her photographs needed to be in colour. In this regard Warburg's work stands out among her peers and in my opinion, she deserves recognition for her pioneering efforts as one of the medium's earliest colour photographers.

Of her other influences, I would suggest that Warburg's role as founder of the Colour Group was central to her inspiration and involvement with so many processes. It is likely that manufacturers would have been contacting her to organize for the demonstration of their products and processes, and as a result Warburg would have always been the first to know of any developments within the market. It would seem that Warburg had few interests outside of photography and few influences outside of the RPS. 
She did however maintain a presence amongst London and international elite groups. In 1910, Warburg became Chairperson of London's Halcyon Club. The Halcyon Club was established as a place for educated, creative women to meet and stay while visiting London. Exhibitions were held there frequently, including one in 1914, which displayed 84 photographs, one of which was Warburg's. Other RPS members belonging to the Halcyon Club include Helen Messinger-Murdoch and Lillian Veley.

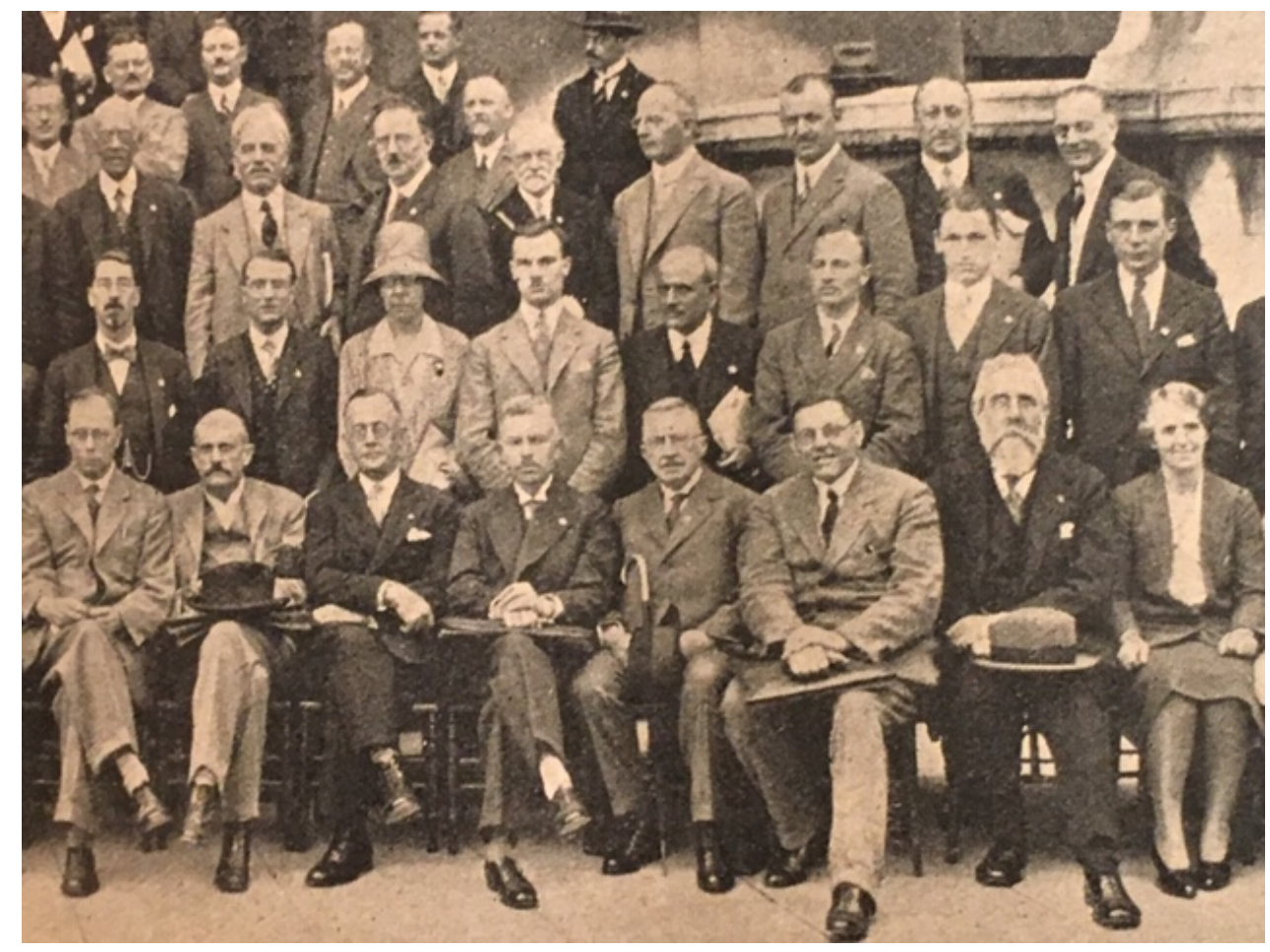

Figure 10. Seventh International Congress of Photography, 1928. Published in the British Journal of Photography (Agnes Warburg, middle row, third from the left; John Cimon Warburg, front row, second from the right)

Her wealth and the freedom it afforded her cannot be overstated. It can be safely assumed that her finances gave her the freedom and stability to pursue an amateur career in colour photography. Warburg never married; instead, she remained her mother's fulltime caregiver in the family home at 8 Porchester Terrace until her mother's death in 1925, at which time she relocated down the street to 52 Porchester Terrace. The vast majority of her photographs were created here, and it became a local hub for the amateur photography community. There she had a darkroom and she frequently hosted RPS meetings and lectures. When she died in 1953, her estate was passed to her niece Margaret Susan Schlesinger (John Cimon’s daughter), and Warburg left her $£ 86,720$ 
pounds: the equivalent of approximately $£ 2.3$ million in 2019 . She did not face the barriers to entry that most others would have, particularly during the war years when most goods were very expensive and in short supply. In 1936, Warburg offered her nephew a loan of $£ 1000$ to start a publishing business. ${ }^{42}$ He stated, "my Aunt Agnes was in 1936, a spinster in her middle sixties" who had all the money in the world. ${ }^{43}$ Fredric wasn't the only recipient of Warburg's largess. In 1932 she gifted a portion of the Box Hill estate, once the home to famous British novelist and poet George Meredith, to the National Trust of England. ${ }^{44}$ The estate is located in Surrey, near to where she eventually settled. She lived at 52 Porchester Terrace until the outset of World War II, when she relocated herself to the village of Minehead, Cornwall. She continued taking photographs there, but as she approached her 70 s, she stopped producing three-colour prints, instead returning to carbon printing and Dufaycolor almost exclusively. Her last photographs are from November 1949, four years before her death at the age of 81, when they were transferred into the Royal Photographic Society collection where they have remained ever since.

Agnes Warburg's life and her practice in colour photography are exemplary of a career driven by the desire to make colour photography accessible to all as both an art form and photographic process. Beginning with the fact that she was taught her craft by John Cimon Warburg, a quintessential amateur in his own right, amateurism was at the core of her practice. At a time when the barriers against making colour photographs were high, Warburg was eager and committed to ensuring that all those interested in making colour photographs could be made privy to her experience. This is understood through her written contributions to BJP and RPS journals, international display of her colour prints, distribution of her financial wealth, and close relationship to the RPS.

\footnotetext{
42 Ibid., 168.

${ }^{43}$ Ibid.

${ }^{44}$ Ibid., 20
} 


\section{Chapter 3: The Culture of Amateur Photography: 1900-1930}

Warburg was wealthy; she did not sell her photographs; she was not the proprietor of a photographic studio nor did she accept commissions; she never charged the public for her workshops and lectures. She spent her days making and experimenting with photography. This brief analysis provides an approach to understand where Warburg and her practice fit within the context of her time period and what is meant by the word 'amateur'. Her career as an amateur photographer was driven by an intense passion for and deep curiosity about a medium where the fields of art and science converged. Warburg's intentions were to create fine art photographs in a time when art museums had little interest exhibiting photography and absolutely no interest in collecting it. However, her photographs were shown across Europe and in North America in the salon exhibitions of groups that shared her photographic passions. By 1914 there were 350 photography clubs in the United Kingdom, most of which can be defined as amateur clubs. ${ }^{45}$ The term amateur is familiar within professional nomenclature: typically unpaid, an amateur is a non-professional, practicing a craft at a level beyond a hobby. In the late $19^{\text {th }}$ and early $20^{\text {th }}$ centuries, the concept of 'amateur' was central to photographic culture and industry. For example, the invention of the innovative Kodak camera with its flexible roll film and ultimately, Kodak itself, was driven by the amateur photographer George Eastman, who developed his early products while working as a bank clerk.

Michael Pritchard suggests that leading up to the 1890s and invention of the snapshot, the notion of the amateur was binary; either you were professional and in studio, or you weren't, and you were an amateur. ${ }^{46}$ He states that as photographic materials and equipment became easier to use and more affordable, the number of amateur photographers increased and the binary of professional and amateur became more distinguished. Alongside the increase in amateurism came more interest in experimentation to better the medium, and consequently, the amateur photographer claimed a place as an essential part in the technical and artistic development of

\footnotetext{
${ }^{45}$ Michael Pritchard, "Who were the amateur photographers?" Reconsidering Amateur Photography, accessed June 30 , 2019, http://eitherand.org/reconsidering-amateur-photography/photographic-histories-actualities-potentialities-/

${ }^{46}$ Pritchard, "Who were the amateur photographers?" Reconsidering Amateur Photography, accessed June 30, 2019.
} 
photography. In this respect, Warburg was the quintessential amateur. This period also subdivided the amateur into snap-shotter and hobbyist, where the hobbyists were continuing to participate in the technological advancement and art of photography and the snap-shotters were simply taking pictures. ${ }^{47}$ The sentiment was that one who simply pressed a button was not worthy of the honourable title of amateur. This continued delineation between 'types' of photographers to include snap-shotter is often linked to the invention of Kodak roll film and the subsequent 'democratization' of photography. However, as Christian Joschke discusses in his essay, "Amateurism and Cultural Change: Photography in Germany and Austria (1880-1900)," segmenting practices within amateur circles of art, science and private life is to "forget about social space, climate of competition, and structures for the exchange and circulation of images." discusses the highly competitive climate between amateur and professionals in the last two decades of the nineteenth century. Professional photographers perceived the skill set and ambition of amateurs as threatening, and in response, amateur photographers were required to clearly define and separate themselves. Firstly, the logic that an amateur would be in any way threatening to the professional landscape would counter the basic freedoms of choice and time that characterized the amateur practice. Amateur photographers, "strived to be of use to all through [their] disinterested willingness to communicate [their] discoveries without hoping to make a living from them, since otherwise, [their] aspiration toward the ideal would be transformed into a drive for profit, pleasure into business, and then [they] would exchange [their] right to the title of amateur for the right to a tax form." ${ }^{49}$ In Britain, the intensely hierarchical structure of art photography built from an illustrious group of men including Henry Peach Robinson, Roger Fenton and Alvin Langdon Coburn, resulted in amateurism's neglect within art historical circles of study and interest at the time. Yet these men shared an intrinsic link to the RPS, a club that was founded on the basis of discussion around photography: a sentiment shared across dividing lines. Sociologist Robert A. Stebbins offers a useful analysis for defining an amateur using the theory that he calls the 'Professional, Amateur,

\footnotetext{
${ }^{47}$ Ibid.

${ }^{48}$ Christian Joschke, "Amateurism and Cultural Change: Photography in Germany and Austria (1880-1900)," in Impressionist Camera Pictorial Photography in Europe (1888-1918), ed. Patrick Daum and Phillip Prodger (London, UK: Merrell Publishers Limited 2006), 107.

49 Joschke, "Amateurism and Cultural Change: Photography in Germany and Austria (1880-1900)," 108.
} 
Public' system. ${ }^{50}$ He states that this interdependence of these three titles is what enables us to separate an amateur from a professional: without one, you cannot have the other. $\mathrm{He}$ states that amateurs serve the public and share the intellectual relationships of professionals, yet have the freedom of hobby, choice and time that are characteristic of the amateur. In respect to photography, scientists relied on amateurs to publish their discoveries and spread awareness of their innovations outside the academic arena. ${ }^{51}$

However, during this time in colour history, the quest to mechanically reproduce colour was largely technically driven and required expensive materials and access to specialized workspaces and tools. In this regard, amateur colour photography differed from the general idea of an amateur who would have been constrained by money and time. It is important to understand that while Warburg worked in this milieu, she had developed highly specialized knowledge and skills relating to colour photography that resulted from her wealth and leisure time.

\footnotetext{
${ }^{50}$ Robert A. Stebbins, “The Amateur: Two Sociological Definitions," in The Pacific Sociological Review 20 no. 4 , (October 1977): 585.

${ }^{51}$ Joschke, "Amateurism and Cultural Change: Photography in Germany and Austria (1880-1900)," 107.
} 


\section{Chapter 4: The RPS Colour Group}

A comprehensive history of the RPS Colour Group is a stand-alone subject that is outside the framework of this thesis project. The following is meant to give an overview of the fundamental workings and structure of the Colour Group that creates another basis for us to deepen our understanding of Warburg's vigorous involvement with colour. She joined the RPS 1916 when she was 44 years old. ${ }^{52}$ At that stage in her career she had been experimenting with colour for nearly a decade, and though I cannot be certain why she chose to join the RPS when she did, I would suggest it was motivated by her desire to collaborate more closely with other photographers. She quickly became an active member of the society, producing images across processes, which eventually lead to her invention of the War-type process in 1918. In 1921 she formed the RPS Pictorial Group, but she is best remembered for her contributions to the RPS Colour Group which she cofounded in 1927 alongside six other RPS members: Violet K. Blaiklock, J. Dudley Johnson, F.J. Tritton, F.G. Tutton, S.H. Watkins and Frank R. Newens. ${ }^{53}$ The object of the group was to further the progress of colour photography "in all its technical and artistic aspects through the medium of authoritarian papers and demonstration pertaining hereto, with an eye to the advantages accruing from discussion of the problems raised and the free exchange of ideas and experiences naturally evoked." ${ }^{54}$ The committee, made up of the seven founding members, met monthly to discuss their successes and challenges, plan the rigorous tutorial and workshop schedule for members, and agonize over the technical elements around displaying colour slides and prints in exhibition. The Colour Group provided Warburg with an official platform to carry out her experiments and collaborate amongst her colleagues. It gave her an arena to share her knowledge with a network that was equally motivated to see colour photography become available to the masses, solidifying the magnitude of influence that Warburg and the amateur community held in perpetuating the growth of colour photography through display, lecture, and the Photographic Journal.

\footnotetext{
${ }^{52}$ Frank R. Newens, "Obituary: Agnes B. Warburg (Fellow)," 111.

${ }^{53}$ Minutes of the Royal Photographic Society Colour Group, "Bylaws of the Colour Group," April 1927, Royal Photographic Society Collection at the Victoria and Albert Museum, XRA 84, (hereafter cited as Minutes, Colour Group).

${ }^{54}$ Minutes, Colour Group, "Bylaws of the Colour Group,” April 1927.
} 
In 1927, the same year that the Colour Group was inaugurated, the annual RPS exhibition included a separate section in the annual exhibition for colour photographs. The group were advocates of colour photography as art across a range of processes, particularly slides, because they were easier and less expensive to make, therefore opening up the market of colour photography to a wider audience. But the anticipation of criticism for their choice to display slides in a rigidly pictorial environment was not lost to them. In preparation, committee meetings were strictly focused on testing brands of glass housings that best rendered colours under artificial and natural light sources. An excerpt from a meeting held May 20, 1928 reads,

"The question of illuminating the colour transparencies for the 1928 Exhibition was discussed and various filter glasses and lamps were tested. It was decided that the daylight filter glass, sent for trial by Messers [sic] Chance Bros., gave the most satisfactory colour rendering for the transparencies under test, of which a number were brought by Miss Bayne, Tritton and Newens. Be it resolved that the Secretary be asked to procure a piece to fit one of the larger cabinets so that it could be tested under Exhibition conditions and that enquiries should be made re exchanging the unsatisfactory blue glass used previous for the kind approved. Further discussion took place with regard to method of arranging the transparencies and finally the suggestion that they should be slid into horizontal runners one inch wide with one-inch dividing strips was agreed upon. Mr. Bay offered to procure the necessary wood so that one case could be fitted for inspection and approval from council.",55

As founder of this group Warburg would have played a fundamental role in perpetuating the idea that slide-based photographs be shown in these exhibitions, and at the highest professional display standards. This demonstrates my argument that Warburg was instructing trends in colour photography in an effort to grow the audience and users of colour photographs.

Six years before Newhall's exhibition Photography 1839-1937, the Colour Group organized their first historical display of colour photography titled Photography in the Service of Mankind (Figure 11) in November 1931. It was a comprehensive display that sought to address all advancements in colour from 1868 to present day, spread across all its applications including scientific research, book illustration, advertising, and art. ${ }^{56}$

\footnotetext{
${ }^{55}$ Minutes, Colour Group, "Committee Meeting," April 20, 1928.

${ }^{56}$ Owen Wheeler, "Colour Photography: The Exhibition Reviewed," The Photographic Journal 72, no. 1 (January 1932): 1.
} 


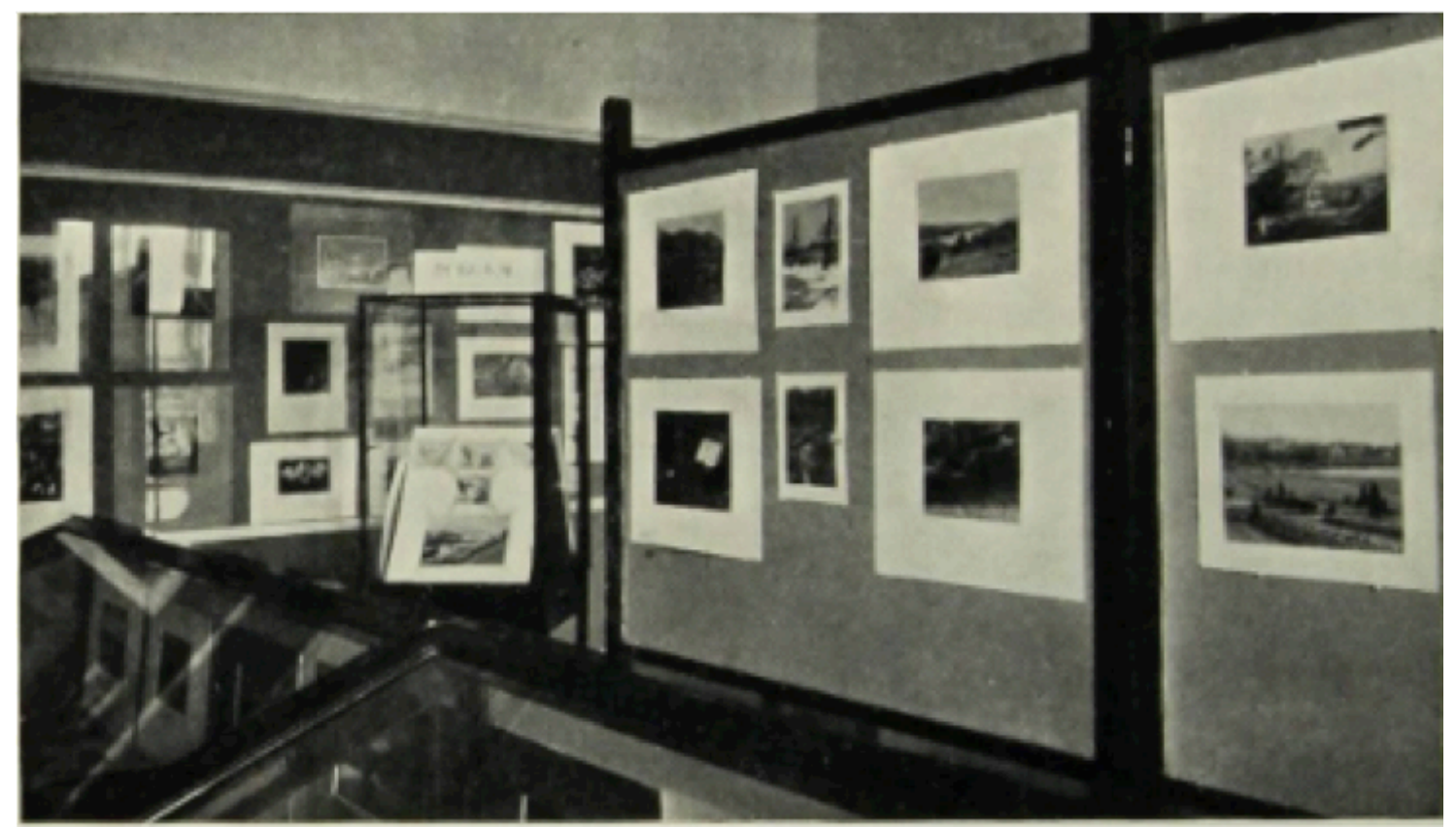

Figure 11. Installation photograph of the RPS exhibition Photography in the Service of Mankind, 1931, from The Photographic Journal, November, 1931.

Photographs printed in the RPS journal show that the exhibition was designed using a combination of salon and modern gallery styles, indicating that they were also aware of the evolution in exhibition design and institutional ideologies that accompanied art photography. RPS member Owen Wheeler reviewed the exhibition in the January 1932

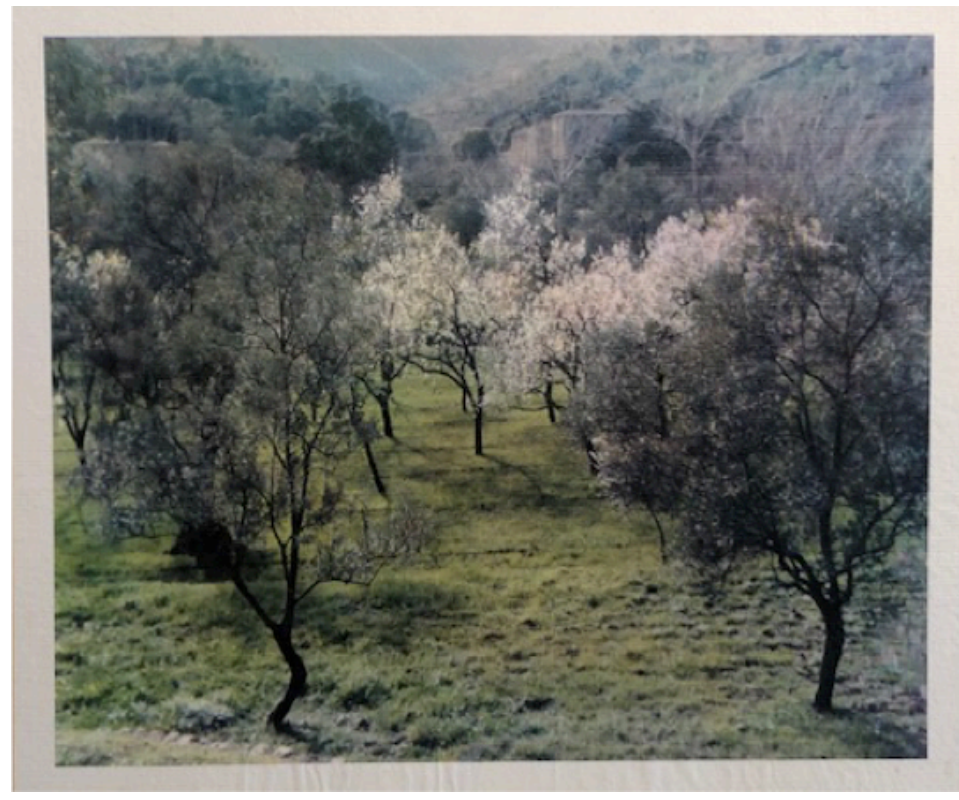

Figure 12. Agnes B. Warburg, Olives and almonds, Majorca, tri-colour carbro print, ca. 1930, (C) Victoria and Albert Museum issue of the journal. Each

section was reviewed

individually: historical,

mechanical colour,

transparencies, subtractive

processes, and apparatus. The

review indicates that several of

Warburg's works were shown

under the subtractive processes

section and prints such as,

'Olives and almonds, Majorca'

displayed the "thoughtful

delicacy" characteristic of her 
acclaimed pictorial style (Figure 12) ${ }^{57}$ As evidenced by a stamp on the verso of the print, it was displayed again in 1938 at the first International Photographic Exposition at the Grand Central Palace in New York City.

Photography in the Service of Mankind provides an example of the role amateur photographers played in the development of colour that dominant histories have neglected to account for. ${ }^{58}$ It also gives a window into the multidimensional character of Warburg, who was not only an aesthetically conscious practitioner, but also participated in the curatorial and exhibit design work through her involvement within this ideologically engaged group of individuals.

\footnotetext{
${ }^{57}$ Wheeler, "Colour Photography: The Exhibition Reviewed," 2.

${ }^{58}$ Gil Pasternak, "Photographic Histories, Actualities, Potentialities: Amateur Photography as Photographic Historiography," Reconsidering Amateur Photography, accessed June 30, 2019.
} 


\section{Chapter 5: Colour Processes}

It is nearly impossible to quantify the exact number of colour processes invented in between 1850 and 1935, as so many never made it past the point of experimentation, let alone to commercial success. In 1924, the New York Public Library issued a catalogue containing approximately 1,450 significant moments in experimentation and colour processes released to date ${ }^{59}$ Irrespective of this list not accounting for the remaining 10 years until the introduction of Kodachrome, this catalogue offers a reference for the fervent level of activity in this field. Of all these processes, the few that did possess the commercial and scientific acumen to make it into the hands of devoted amateurs, like Warburg, were certain to receive diligent use and attention.

Warburg used as many as nine processes between 1887 and 1949. The diverse range of processes she used characterizes her as a critical subject within the study of early

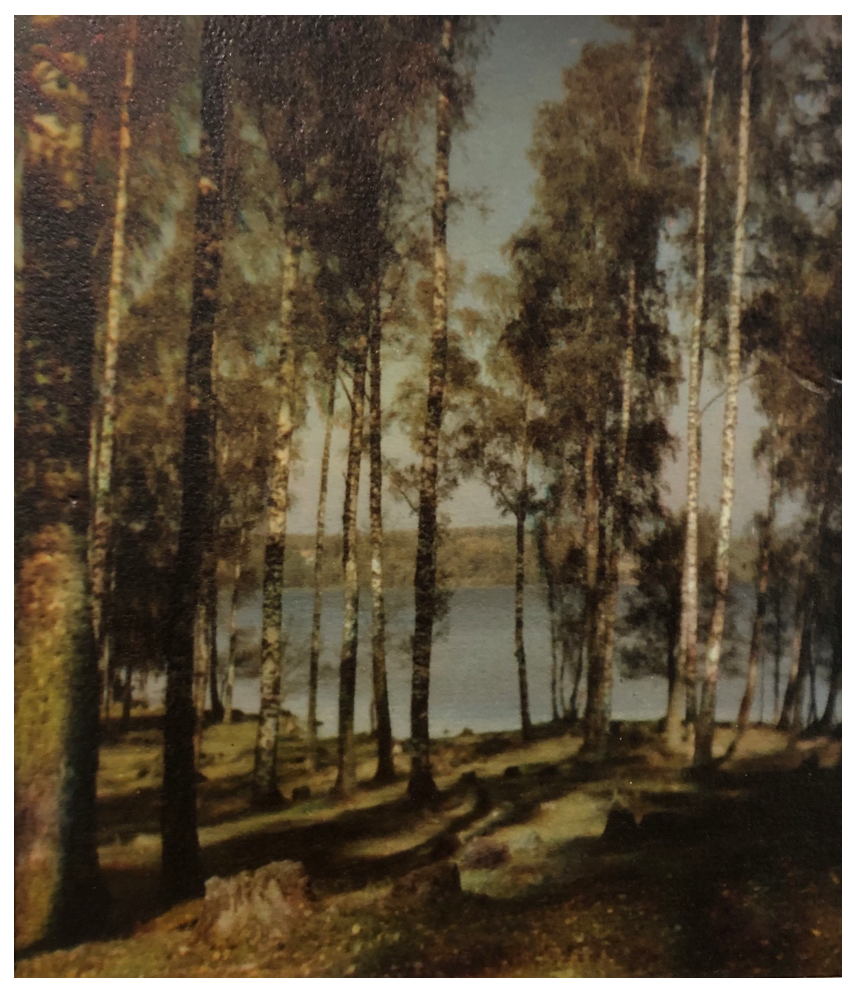

Figure 13. Agnes B. Warburg, Autumn by the Lake, Gudhammar, Sweden, tri-colour carbro print, 1927 (C) Victoria and Albert Museum colour photography and photographic history more widely. The multitude of processes reflects her interest in the medium when few others were, and illuminates her unique practice that was built out of the RPS network. Analysis of these processes allows us better understand Warburg's importance to the history of colour, and simultaneously provides a deeper understanding of photographic history that is linked to amateur networks. By nature of the time period she was working in, each colour process possessed certain technical limitations

\footnotetext{
${ }^{59}$ William Burt Gamble, Color Photography: A list of references in the New York Public Library, (New York, NY: New York Public Library, 1924), accessed July 10, 2019, https://archive.org/details/colorphotography00newy/.
} 
that inhibited her artistic practice, encouraging her to experiment with alternative processes. Beyond what colour restricted her in creating, she recognized the potential of colour, and experimented with these processes as a way to broaden colour photography's capabilities. This is demonstrated by her participation in tutorials offered by the Colour Group and lecturing to her peers, but most importantly, through her invention of the Wartype. This chapter will describe and interpret her activity with these processes and will include a discussion on how each one relates to the broader Warburg collection.

The nine processes she used include: platinum, carbon, tinted gum arabic, the autochrome, Raydex/Ozobrome, the War-type, tri-colour carbro, Kodak Colorsnap, and Dufaycolor. This list can be divided into two categories: assembly processes and screen processes. The assembly processes she used were gum printing, Raydex/Ozobrome, tricolour carbro, Colorsnap and the War-type. All were printed tediously by hand, sometimes taking many days to develop. By comparison with the simpler screen processes such as the autochrome and Dufaycolor these assembly processes were extremely difficult to use. Fundamentally, screen-based processes like the autochrome changed the modus operandi of making photographs. Making colour photographs was no longer about control in the darkroom or experimenting with pigments and dyes, as most amateur and professional photographers could successfully develop autochrome slides. However, the autochrome and other mechanical processes that were to come posed a great challenge to pictorialists, who were concerned with evoking colour as opposed to mimicking it. ${ }^{60}$ Warburg's collection of assembly and screen processes indicates that she was aware of the perceived artistic limitations of the autochrome and it could be argued that that is what drove her to pursue such a diverse range of assembly processes. The assembly processes produced a print instead of a slide, while offering greater ability for control to evoke rather than mimic the colours that surrounded her. From 1907 until the late 1930s Warburg was working exclusively with these print materials. Her career as a colour photographer was capped by the use of two screen processes, the autochrome and Dufaycolor. Yet the two differ starkly in quantity, quality and content in the Warburg

\footnotetext{
${ }^{60}$ Nathalie Boulouch, “Autochromes and Pictorialism: An Element of Colour in a Monochrome Universe," in Impressionist Camera Pictorial Photography in Europe, 1888-1918, ed. Patrick Daum and Phillip Prodger (London, UK: Merrell Publishers Limited 2006), 269.
} 
collection. There are hundreds of Dufay slides compared to only a handful of autochromes, suggesting that as photographic trends and technologies progressed, Warburg was transitioning her practice alongside these innovations.

The Photographic Journal published by the RPS and the British Journal of Photography (BJP), were central sites for discussion and marketing of different colour process. Warburg was a frequent contributor to The Photographic Journal publishing lectures, articles, and how-to guides for Dufaycolor and tri-colour carbro printing. Collating the textual materials with references to the photographs has enabled me to fill in some of the layers that made up her interdisciplinary practice. The following chapter will outline each of the processes Warburg used to make photographs over the course of her career; beginning with platinum and carbon printing in the late 1800s and culminating with Dufaycolor in the 1940s. The processes can be sectioned into three larger process groups: additive screen processes, pigment processes, and dye imbibition processes. A brief description of how these processes worked and how they were made will be outlined, followed by a discussion on their relevance within the broader Warburg collection.

\section{Platinum and Carbon (1890-1900)}

Warburg followed in the footsteps of her eldest brother, John Cimon Warburg, and began making photographs in the late 1880s. The earliest prints in the V\&A collection are platinum prints made in 1898 though I do not suggest this was the first print she ever made. She used black and white materials throughout her entire career and addressing these images allows us to gain a better understanding of her transition to colour. Her knowledge of black and white materials, processes, and techniques including control of contrast, tonal range and darkroom chemistry all stood her in good stead as she moved into colour printing. By the turn of the century, black and white materials were becoming easier to use, but for those developing at home it was by no means as simplistic as the Kodak suggestion, 'You press the button, we do the rest.' Carbon and platinum printing were multi-step processes requiring intense precision and attention to all key factors: water temperature, solution ratios, development times, chemical balance and 
paper type. The complexity of these processes built her technical skill, which later served her in using colour processes that required the use of black and white separation negatives such as Raydex/Ozobrome, the War-type and Colorsnap prints. Because she was technically proficient, focused, and financially capable I would suggest that she was motivated by the challenge that colour photography posed.

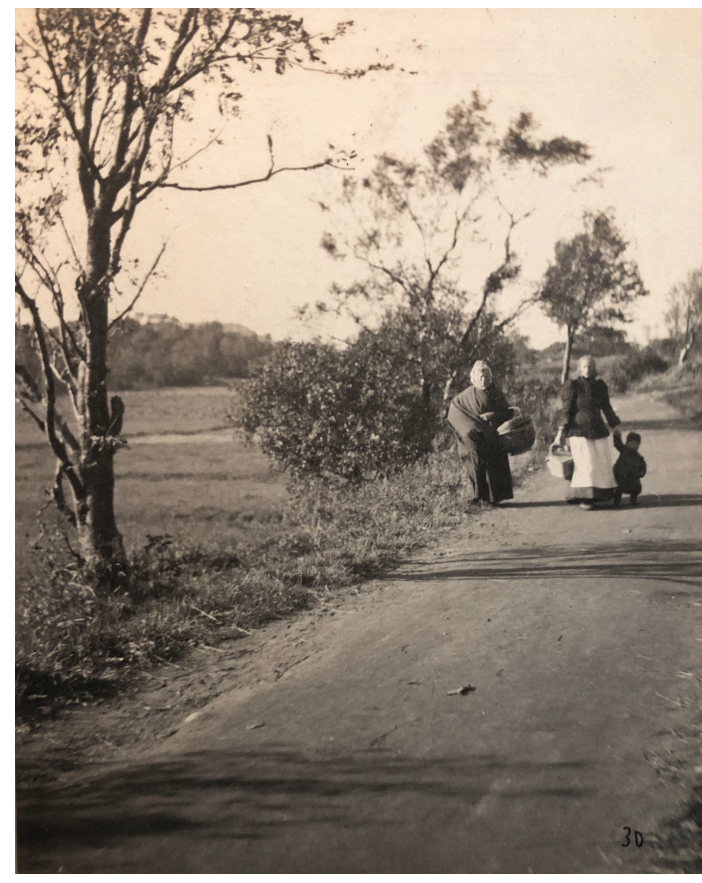

Figure 14. Agnes B. Warburg, A breezy morning near Gothenburg, Sweden, platinum print, 1898 (C) Victoria and Albert Museum

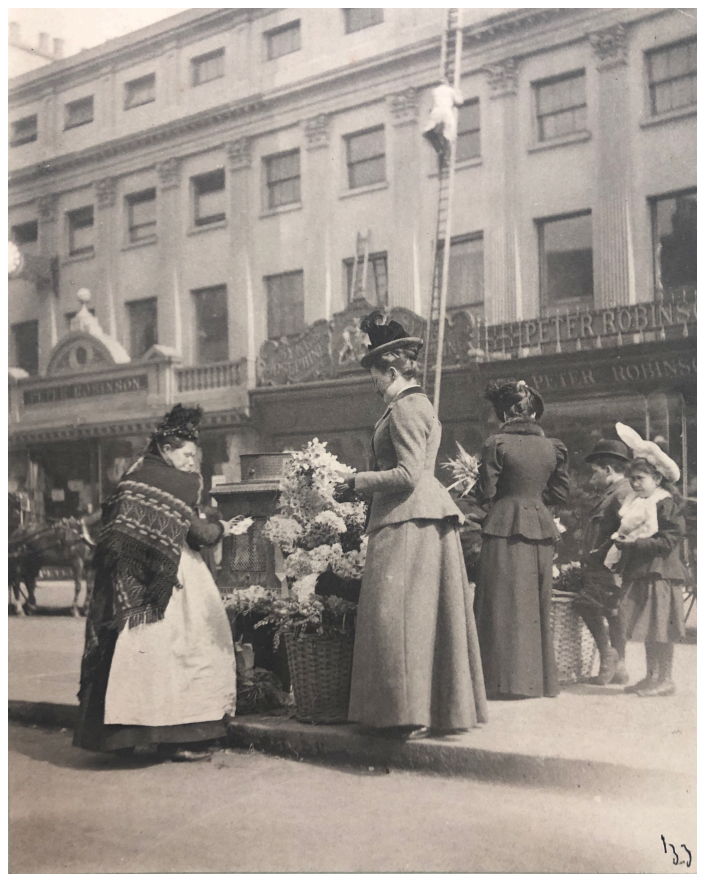

Figure 15. Agnes B. Warburg, Buying Flowers, platinum print, ca. 1899 C Victoria and Albert Museum

\section{Additive Screen Processes}

Warburg's transition to colour began with these processes. Her tinted gum and carbon prints suggest an early inclination toward colour, but it was the invention of the autochrome that solidified her interest in this type of photography. Additive colour screen processes worked on the premise that a colour image could be created through the use of a colour screen in combination with a black and white negative emulsion. These processes enabled shorter exposure times and necessitated fewer exposures than competing colour technologies. The most iconic of the additive processes was the autochrome, introduced in 1907 by the Lumière Brothers. This launched a frenzy of research around the best ways to simulate colour using the additive approach. Myriad processes came forward and some processes, including Dufaycolor, were used well into 
the 1950s. Originally on glass substrates, these processes increased in usership as lighterweight flexible celluloid bases became more widely available in the early $20^{\text {th }}$ century.

Louis Ducos du Hauron established the logic for additive processes in $1868 .{ }^{61} \mathrm{He}$ was the first to consider that photographing through screens comprised of lines of varying colours could enable the first steps required to create a colour photograph. Taking inspiration from Ducos du Hauron, John Joly commercialized the first screen plate process called the Joly Plate in 1897. Despite its high price and fundamental issues of low sensitivity and poor colour quality, it was the first process to gain any real popularity and remained on the market until $1900 .{ }^{62}$ Ducos du Hauron would eventually invent the Omnicolore process in 1907, but it fell short on quality and had no commercial success.

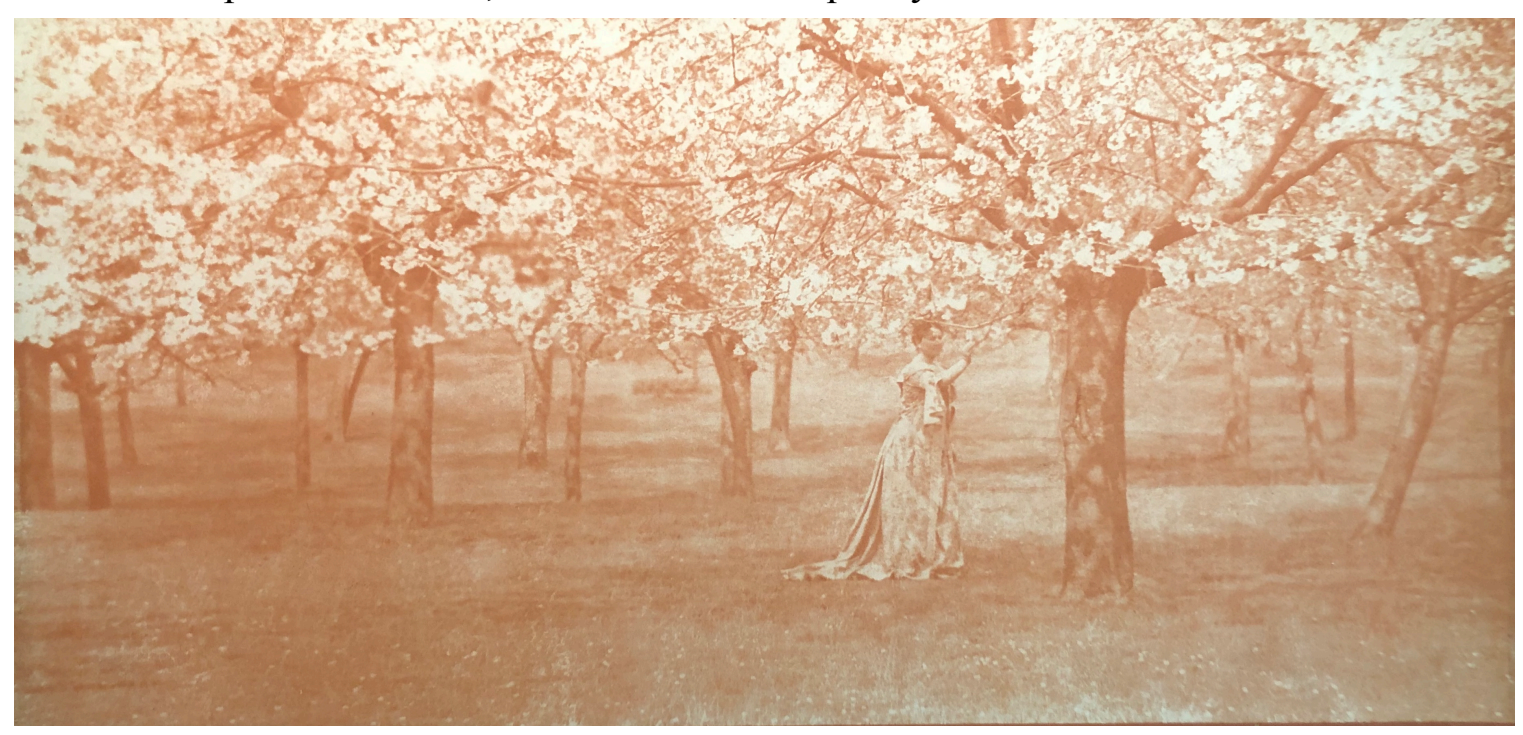

Figure 16. Agnes B. Warburg, A Cherry Orchard in Spring, sanguine-tinted gum print, 1904 C Victoria and Albert Museum

\section{Autochrome}

The autochrome is heralded as the first commercial process capable of photographically rendering the world's natural colours. As evidenced by a patent submitted in May of 1904, the autochrome was ready for issue, but an additional three

\footnotetext{
${ }^{61}$ Penichon, Twentieth Century Colour Photographs, 22.

${ }^{62}$ Ibid., 22.
} 
years of developmental work was required to make it a useable commercial product. ${ }^{63}$ By comparison to other commercial colour process that came before it, exposure times were shorter, resolution was higher, and the colour cast was more accurate. The autochrome used a combined system, meaning the screen and photographic emulsion were together on one substrate. Separate systems required that the emulsion plate and viewing screen were separate. Bringing the screen and emulsion together reduced "problems of uneven contact and poor registration between screen and image. ${ }^{\prime 64}$ The autochrome screen was made of up potato starch granules approximately 12 to 15 microns in diameter, dyed blue-violet, orange-red and green, totalling an average of 4,000,000 granules per square inch. ${ }^{65}$ When mixed, the granules created a grey powder that was applied to a glass plate coated with adhesive resins, and gaps between the colour granules were filled with fine black carbon powder ${ }^{66} \mathrm{After}$ being passed under a high-pressure roller, the plate was covered in a layer of nitrocellulose, dammar resin, and castor oil. Finally, a silver-halide photosensitive solution was coated over the screen. Developing a plate was done using a conventional reversal technique, a process that produced a positive image directly onto the substrate. Once the picture was developed it would be bleached and re-exposed to white light and developed a second time to produce a positive image. The resulting positive image would then be varnished and protected with a piece of glass. ${ }^{67}$

The soft, painterly quality of the autochrome initially put it in good stead amongst the artistic community. Dominant voices in photography, including Alfred Stieglitz, enthusiastically equated its creation with that of the Daguerreotype. ${ }^{68}$ But it was expensive, delicate, and nearly impossible to display. For amateurs similar to Warburg, the need to display slides was paramount. The emulsion covering the plate was so dense that only 7.5 percent of available light was able to pass through the image. ${ }^{69}$ This made

\footnotetext{
${ }^{63}$ Lavédrine and Gandolfo, The Lumière Autochrome, 70.

${ }^{64}$ Penichon, Twentieth Century Colour Photographs, 26.

${ }^{65}$ E.J. Wall, "Introduction," in Color Photography: A list of references in the New York Public Library (New York: New York Public Library, 1924), 4, accessed July 26, 2019, https://archive.org/details/colorphotography00newy/.

${ }^{66}$ Lavédrine and Gandolfo, The Lumière Autochrome, 165.

${ }^{67}$ Ibid., 165.

${ }^{68}$ Alfred Stieglitz, "The New Color Photography - A Bit of History," Camera Work 20 (October1907), accessed July 20, 2019, http://www.photocriticism.com/members/archivetexts/photocriticism/stieglitz/stieglitzcolor.html

${ }^{69}$ Caroline Fuchs, “Anticipation and Reality: A reevaluation of Autochrome Projection," PhotoResearcher, no. 19 (2013): 33 .
} 
viewing the autochrome, under either natural or artificial light, extremely difficult. And to further complicate matters, if a hot projection light source were placed close to the plate, the emulsion would burn and deteriorate quickly. ${ }^{70}$ Lecture, exhibition and demonstration were at the core of the RPS and the challenges members faced in displaying autochromes offers a suggestion as to why Warburg may have discontinued working with the autochrome so early on in her career with colour. The shortcomings of the autochrome resulted in a multitude of new additive screen alternatives, but few would achieve comparable commercial success. Lumière discontinued the autochrome in 1934, a date that seems surprisingly late given the technical advancements that had been happening elsewhere in the market.

Figure 17. (Below left) Agnes B. Warburg, [Untitled], autochrome, ca. 1907, C Victoria and Albert Museum Figure 18. (Below right) Agnes B. Warburg, [Untitled], autochrome, ca. 1907, (c) Victoria and Albert Museum
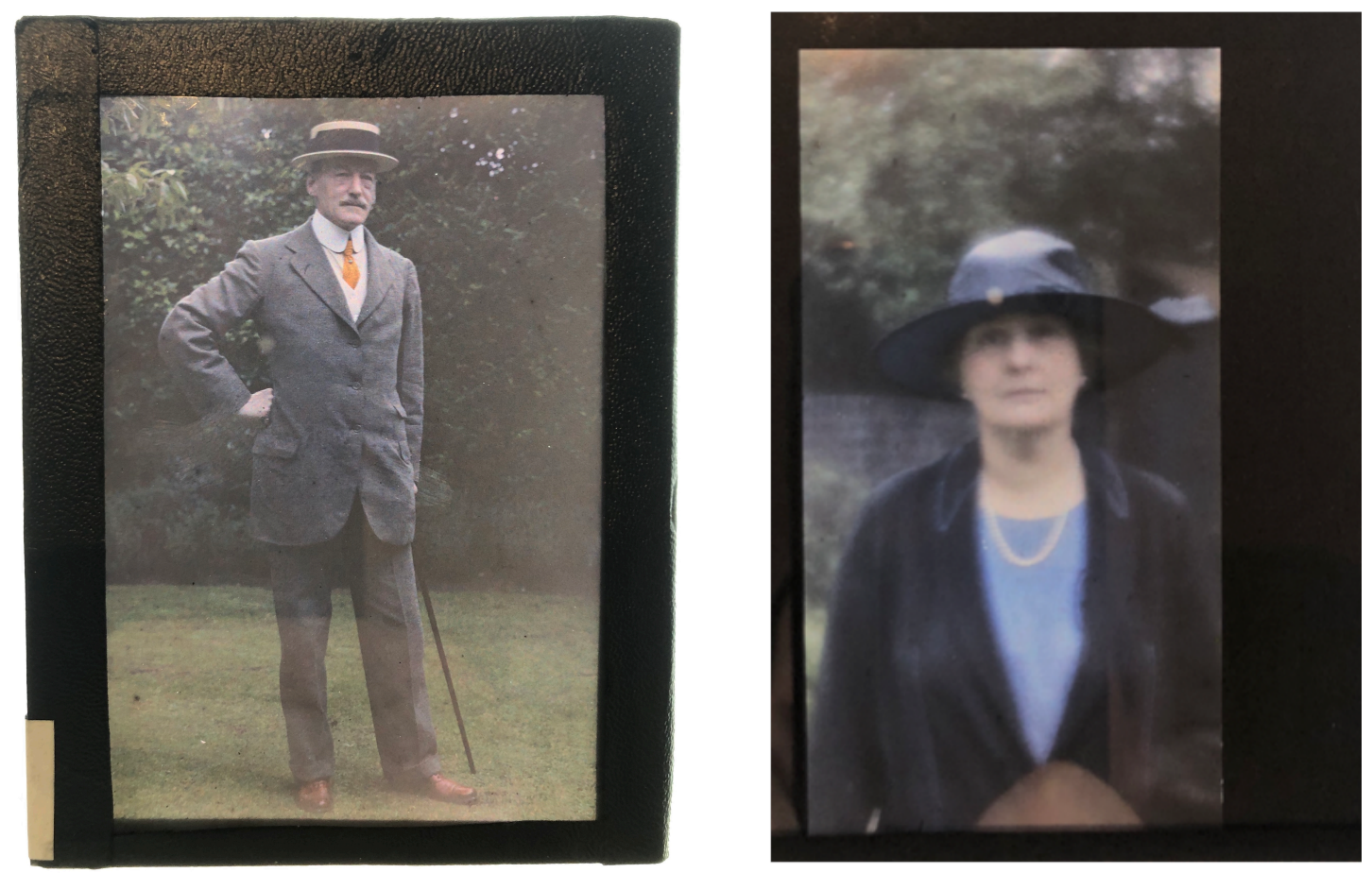

It can be suggested that the collection of autochromes by Warburg represent a very tentative introduction to colour photography. There are approximately twenty plates directly attributable to her. Though there may be more, I hesitate to say so because of the current organization of the collection. Several artists share boxes and the slides are seldom signed. The subjects of the autochromes attributed to her are often out of focus

\footnotetext{
${ }^{70}$ Fuchs, “Anticipation and Reality: A reevaluation of Autochrome Projection,” 33.
} 
and posed. Portraits are not common elsewhere in the collection, and perhaps this was the result of the difficulty associated with capturing a moving, breathing target with a slow shutter speed required for the low light sensitivity of the autochrome plates. Furthermore, it is uncharacteristic of Warburg not to explain her errors or shortcomings in publications or notes on the margins of her images. Therefore, I suggest that these autochromes are the results of Warburg's early experiments with additive colour plates and the first example where we see Warburg abandon a process in favour of one that she felt facilitated better results. In this instance, she moved from the autochrome to tri-colour carbro printing.

\section{Dufaycolor}

Dufaycolor was originally created for motion picture film in 1932, and was introduced to the still photography market in $1935 .^{71}$ Additive process technologies had evolved substantially between Warburg's use of the autochrome and Dufaycolor.

Dufaycolor was the third iteration of film produced by French lawyer Louis Dufay (18741936). Invented in 1908, Dioptichrome was the first of the three, using the basic principles of filtered light put forward by Ducos du Hauron. ${ }^{72}$ This process was a glass plate separate system. Up until the widespread use of film, additive processes were generally all separate systems, meaning that the viewing screen and substrate were created and functioned separately. A major drawback of the separate system was the parallax effect. This occurred when the positive image was not at a right angle to the line of vision. The result was a skewed interpretation of colours: the viewer would see the subject in its complementary colour as opposed to true ones. ${ }^{73}$ Like many other separate systems including Paget and Finlay colour, the effort to eliminate this issue was realized when combined systems were invented. For Dufay, this was Dioptichrome-B, released in $1910 .^{74}$ The Dufay Company was dissolved prior to World War I, but would be picked up again in 1917 under the name Dufay Versicolor. ${ }^{75}$ In 1925, the company changed hands

\footnotetext{
${ }^{71}$ Barbra Flükiger, "Dufaycolor," Timeline of Historical Colours, 2012, accessed February 15, 2019, https://zauberklang.ch/filmcolors/timeline-entry/1257/?_sf_s=dufay

${ }_{73}^{72}$ Lavedrine and Gandolfo, The Lumière Autochrome, 94.

${ }^{73}$ Penichon, Twentieth Century Colour Photographs, 314.

${ }^{74}$ Ibid., 314.

${ }^{75}$ Fiona Vaughn, "Dufaycolor: materials, techniques and deterioration," The Australian Institute for the Conservation of Cultural Materials (AICCM) Bulletin 31, (2008): 56.
} 
again. ${ }^{76}$ The family-run English company, Spicers Ltd., of London sponsored the process in 1932, renaming the company Spicer-Dufay. ${ }^{77}$ Together with the Spicer Ltd. engineer, Charles Bonamico, they released the first iteration of Dufaycolor as ciné film in $1932 .^{78}$

In 1935, Ilford Limited of London purchased the manufacturing rights and started making $35 \mathrm{~mm}$ and $2 \frac{1}{4}$ inch film for still photography. Using a colour screen, called a mosaic or réseau, the principle of Dufaycolor was the same as many combined additive processes. The réseau was uniformly divided into microscopic areas of blue, green and red that sat on top of an emulsion layer. There were approximately 1,000,000 tiny coloured elements per square inch of film. Together they acted as the filter to create the sensation of colour. The Dufaycolor réseau had alternating rows of blue, red and green dye at a 23-degree angle to one another. The first step in manufacturing a réseau filter was to cover a piece of cellulose acetate (film) with a layer of collodion dyed blue. Greasy ink would then be printed on top and the film would be bleached to create blue channels between clear channels. Next, the film was dyed green to create alternating green and blue lines and the greasy lines would be gone. A new set of ink was rolled on perpendicular to the green and blue lines, and then bleach and dyed in red, again, removing the ink and leaving a completed réseau. ${ }^{79}$ The screen was then coated with a panchromatic emulsion and was ready for exposure. Dufaycolor was sold as cut film, or rolls of 12 exposures. ${ }^{80}$

Warburg was an avid user of the Dufaycolor process. She praised the simplicity of developing an image stating that after decades of having used tri-colour processes, "developing Dufay slides is as easy as falling off a log." ${ }^{.81}$ This part of the collection is comprised of 400 slides, and makes up the majority of the RPS Warburg collection. It was the only process she used in the later part of her life. The last photographs made by Warburg are Dufaycolor slides in 1949: she was 77 years old.

\footnotetext{
${ }^{76}$ Coe, Colour Photography, 72.

${ }^{77}$ W.H. Carson, “The English Dufaycolor Film Process," (London, UK: Dufaycolor Ltd., July 1934), 19.

${ }^{78}$ Carson, "The English Dufaycolor Film Process," 19.

${ }^{79}$ Penichon, Twentieth Century Photographs, 47.

${ }^{80}$ Carson, "The English Dufaycolor Film Process," 19.

${ }^{81}$ Agnes Warburg, "Highland Holiday," The Photographic Journal 161, no. 7 (July 1937): 438.
} 
The Colour Group meeting notes indicate that she was determined to find the best way to display slides for the public: in exhibitions, lectures and at home to friends She felt that the slide was indicative of colour photography's mechanized future. The earliest images in the collection of Dufay slides are from 1935, but notes from a Colour Group meeting hosted on January 7, 1928, show that there was plans for Spicer-Dufay company representative, John Thorne-Baker, to give a demonstration of the Spicer-Dufay process on November 3 of that year. ${ }^{82}$ Her earliest works using Dufaycolor demonstrate a distinct motivation to control the technical quality of the image. Under- and over-exposed images as well as 'perfect' images contain details of exact technical information including time and date photographed, f-stop and exposure time (Figure 19 and 20). This can be interpreted as another means in which to understand Warburg's engagement with colour processes. During this time colour processes shared an intrinsic link to science, and by tracing the technical evolution of film material we see evidence of Warburg as someone deeply involved in the progress of colour photography's technical components. Her practice of documenting technicalities is not seen throughout the entire collection, suggesting that the improvements in technical information around exposure times, colour resolution etc., reduced the need for such meticulous monitoring.

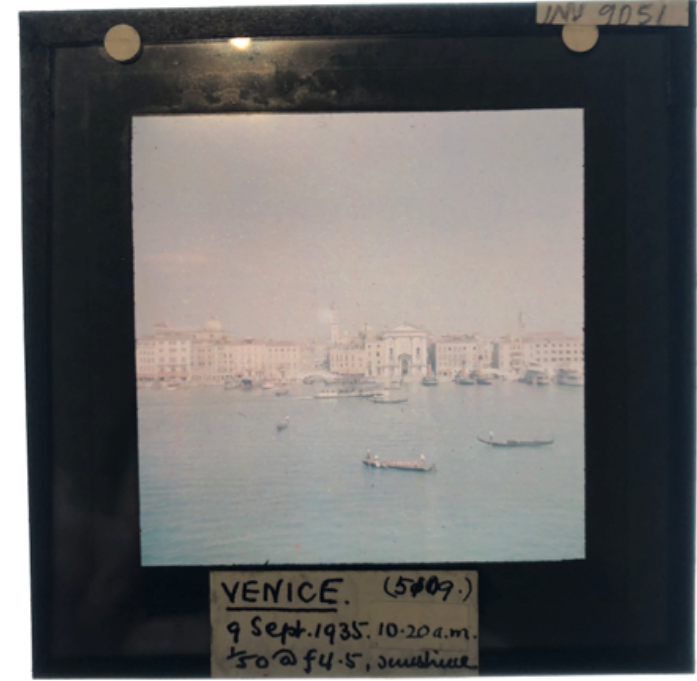

Figure 19. (Above right) Agnes B. Warburg, 5109. Venice,9 Sept 1935,10:20am,1/50@f4.5, sunshine, Dufaycolor slide, 1935, (C) Victoria and Albert Museum

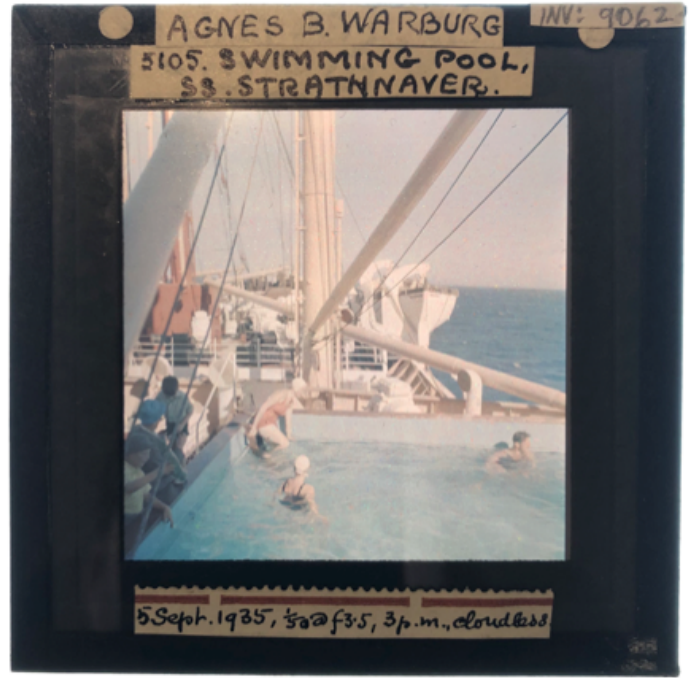

Figure 20. (Above left) Agnes B. Warburg, 5105. Swimming pool, SS Strathnaver, 5Sept 1935, 1/50@ f3.5, 3p.m., cloudless, Dufaycolor slide, 1935, (C) Victoria and Albert Museum

\footnotetext{
${ }^{82}$ Minutes, Colour Group, “Committee Meeting,” October 14, 1931.
} 


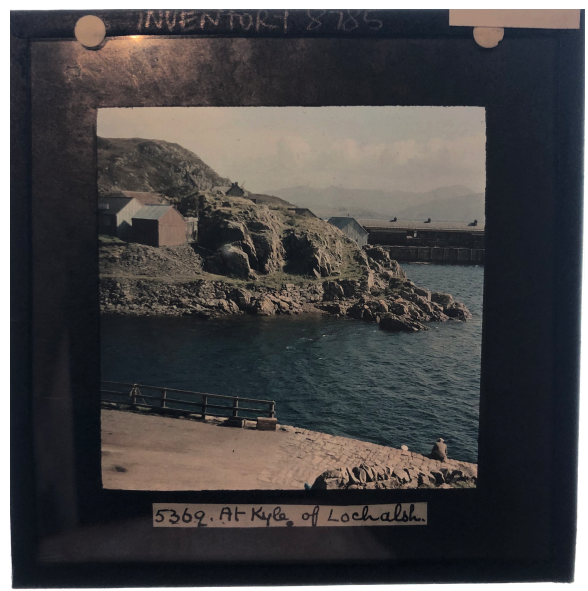

Figure 21. Agnes B. Warburg, 5369. At Kyle of Lochalsh, Dufaycolor slide, 1937, (C) Victoria and Albert Museum
In 1937, Warburg gave a lecture to RPS members on a selection of slides she had made during a trip to Scotland. Evidenced by a series of notes in the collection, these slides were of various sizes and developed at home using various 'brews'. ${ }^{83}$ The associated RPS journal review of this lecture indicates that she exposed approximately nine rolls of Dufaycolor film on this trip, and of those 108 photographs captured, the collection holds 77. The institutional model of photographic history suggests that to consider a slide an art object would be unacceptable, but not according to Warburg and her peers. Frank Newens, the Chair of the Colour Group and attendee of lecture said,

"it is difficult to find words to express all they felt about the slides Miss Warburg had shown. They were among the best they had seen and reflected credit on both, Miss Warburg for her beautiful sense of composition and wonderful processing, and on the Dufaycolor process for the way it had reflected the colours."

The meticulous naming, dating and framing of slides were the result of extensive deliberation by the Colour Group. It was decided that in order to display slides in exhibition, the author's name, and an image title had to be written on the margin. Only certain sizes of slides would be considered for display, those being: 3 1/4 x $3 \frac{1}{4}, 4 \frac{1}{4} \times 3 \frac{1}{3}, 6 \frac{1}{2} \times 4 \frac{3}{4}, 8 \frac{1}{2} \times 6 \frac{1}{2}$ inches. All of Warburg's slides are $31 / 4 \times 3 \frac{1 / 4}{4}$. Rules of size only applied to the slide itself-cropping and content decisions rested with the author. Image

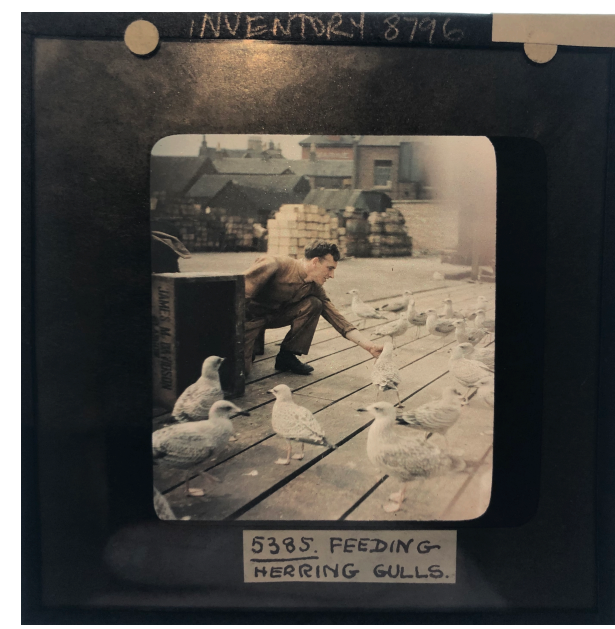

Figure 22. Agnes B. Warburg, 5385. Feeding Herring Gulls, Dufaycolor slide, 1937 (C) Victoria and Albert Museum

\footnotetext{
${ }^{83}$ Agnes Warburg, hand-written notes titled "Highland Holiday Explained," 1927, Royal Photographic Society Collection, XRG 194.

${ }^{84}$ Warburg, "Highland Holiday," 438.
} 
cropping, likely done using an external camera frame, is frequently seen in this collection. ${ }^{85}$

\section{Additive Colour Screen Printing}
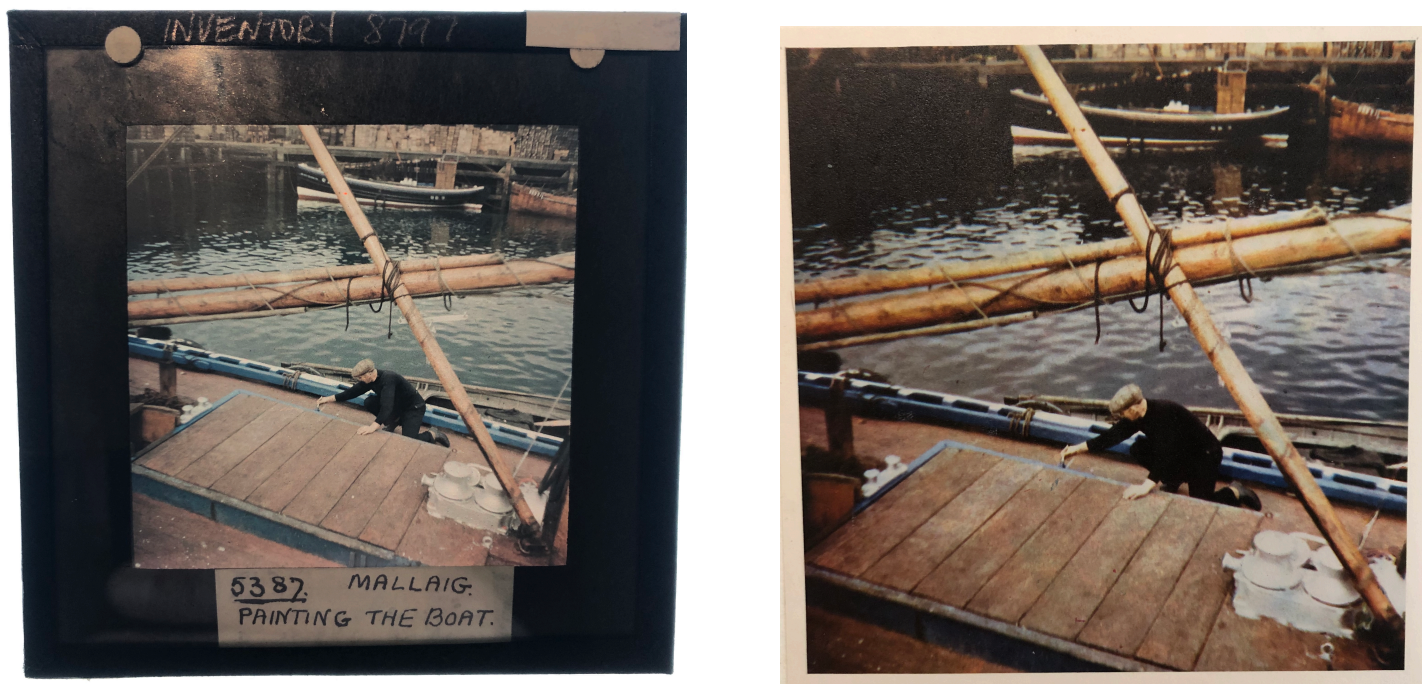

Figure 23. (Above left) Agnes B. Warburg, Mallaig, painting the boat, Dufaycolor slide, 1937, (C) Victoria and Albert Museum

Figure 24. (Above right) Agnes B. Warburg, Mallaig, painting the boat, tri-colour carbro print, ca. 1937, (C) Victoria and Albert Museum

Printing from additive colour screen transparencies was a common commercial practice. ${ }^{86}$ By producing colour separation negatives, publications could convert slides into prints using pigment, imbibition and dye-mordanting processes. As a result of Warburg's existing expertise in monochrome pigment printing it is safe to assume that she welcomed the opportunity to use these similar print-making processes and techniques in colour. There are several images in the collection that were produced first as Dufaycolor slides and then again as pigment prints. To make a print, separation negatives were created using from the slides using 'block-out' screens. Most companies making additive screen slides, including Dufaycolor, manufactured these screens and they were sold as part of the kit. Block-out screens were "arranged in the same pattern as the original taking screen but blocking out all but one of the colour pattern."87

\footnotetext{
${ }^{85}$ Minutes, Colour Group, “Committee Meeting," October 2, 1929.

${ }^{86}$ Penichon, Twentieth Century Colour Photographs, 53.

${ }^{87}$ Ibid., 54.
} 


\section{Dye Imbibition Processes}

The word imbibition is defined as the absorption of one substance by another; in relation to a photograph, dye is absorbed by gelatin. The earliest notions of dye imbibition processes are attributed to Charles Cros (1842-1888) and Ernest Edwards (1837-1903). Building off of ideas of put forward by Edwards in 1875, Charles Cros patented a tri-colour imbibition process called hydrotypie in $1880{ }^{88}$ Imbibition processes are assembly processes, meaning that "the image is built up by the successive transfer of coloured layers onto a final support." ${ }^{, 89}$ One of the earliest examples of a dye imbibition process was the Sanger-Shepherd process, invented in 1900 by RPS fellow Edward Sanger-Shepherd. Creating a Sanger-Shepherd slide involved exposing three sensitised pieces of celluloid, called matrices, through different coloured filters to create gelatin reliefs. Each relief was then stained in carefully calculated solutions of yellow, cyan and magenta dyes. The coloured reliefs would then be rolled individually onto a separate substrate in perfect registration to create an image. ${ }^{90}$ But because the dyes tended to wander, developers seldom printed the images onto paper. Instead, they chose to create transparencies by overlaying the matrices and placing them between two pieces of glass. This process would become a catalyst for the creation of other imbibition processes to come, most famously, the Kodak Dye Transfer process, developed in 1946.

\section{Colorsnap}

Colour Snap Shots London Limited introduced the Colorsnap process in 1929. ${ }^{91}$ Colorsnap was a tri-pack system: a singular unit of film containing "three emulsion layers of different sensitivity, each on its own base, used to obtain three separation negatives with a single exposure. $" 92$ As with many other tri-pack systems, Colorsnap was flawed. The tri-pack system required that light pass through all three layers of support and emulsion, which often led to one of more of the negatives being blurred or low in resolution. ${ }^{93}$ This issue was so prevalent that Color Snap paid workers to hand-colour

\footnotetext{
${ }^{88}$ Ibid., 128.

${ }^{89}$ Ibid., 126.

${ }^{90}$ Ibid., 128.

${ }^{91}$ Ibid., 136.

${ }^{92}$ Ibid., 314.

${ }^{93}$ Coote, The Illustrated History of Colour Photography, 108.
} 
monochrome prints from the best of the three negatives from the tri-pack. ${ }^{94}$ As a result, this printing process was off the market before the end of 1929, the same year it was introduced. The system was later licensed by Agfa-Ansco in America, a company that specialized in film production and printing, but issues persisted and it was discontinued in $1934 .^{95}$

This blurry, high contrast and oversaturated picture is the only Colorsnap print in the Warburg collection (Figure 25). My suggestion is that it was the product of a tutorial offered by the Colour Group; however, I cannot establish evidence to confirm this. Meeting notes from April 1932, state that Color Snap Limited was to host a tutorial, though the photograph in the collection is dated 1929. ${ }^{96}$ Perhaps there was more than one tutorial hosted; perhaps her exploration of this process was self-guided. This furthers the idea that Warburg's use of such a range of processes was motivated by the technical limitations they presented. Furthermore, it reminds us of her leadership role within the Colour Group that would have kept her aware of changes and developments within the photographic industry.
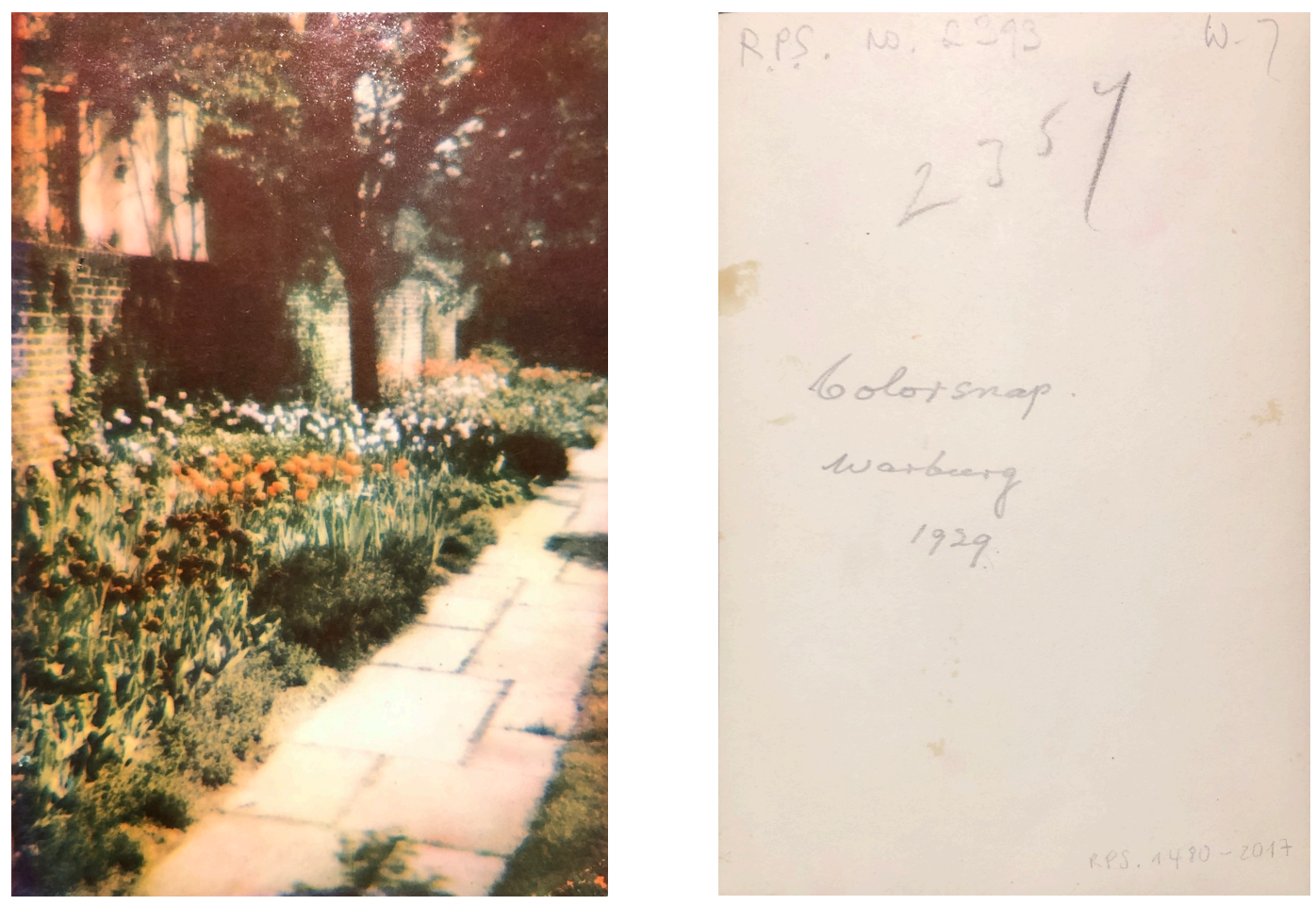

Figure 25. Agnes B. Warburg, Colorsnap [recto and verso], Colorsnap print, 1929 @ Victoria and Albert Museum

\footnotetext{
${ }_{94}^{9}$ Penichon, Twentieth Century Colour Photographs, 136.

${ }^{95}$ Ibid., 136.

${ }^{96}$ Minutes, Colour Group, “Committee Meeting,” April 1932.
} 


\section{Pigment Processes}

The desire to create images on paper was realized with forms of pigment processes. In comparison to glass-based substrates, a picture on paper was easier to display and circulate, which made paper the ideal substrate. Coloured carbon prints, gum prints and carbro prints are the three types of pigment prints, all of which are present in the Warburg collection. To this day, these pictures are the most stable of all the colour processes; however, at the time of their invention they were difficult and costly to make. Louis Ducos du Hauron was the first to describe ideas around subtractive printing processes on paper, called heliochromy. ${ }^{97}$ His logic was the basis of all processes to come; he stated, "If it is true that three colors produce, by the mixture that results from their superposition, all the colors, it follows, per contra, that any picture...may in the mind decompose itself into three pictures, the one red, the other blue, the third yellow, the superposition and incorporation of which reconstitute the same picture." 98

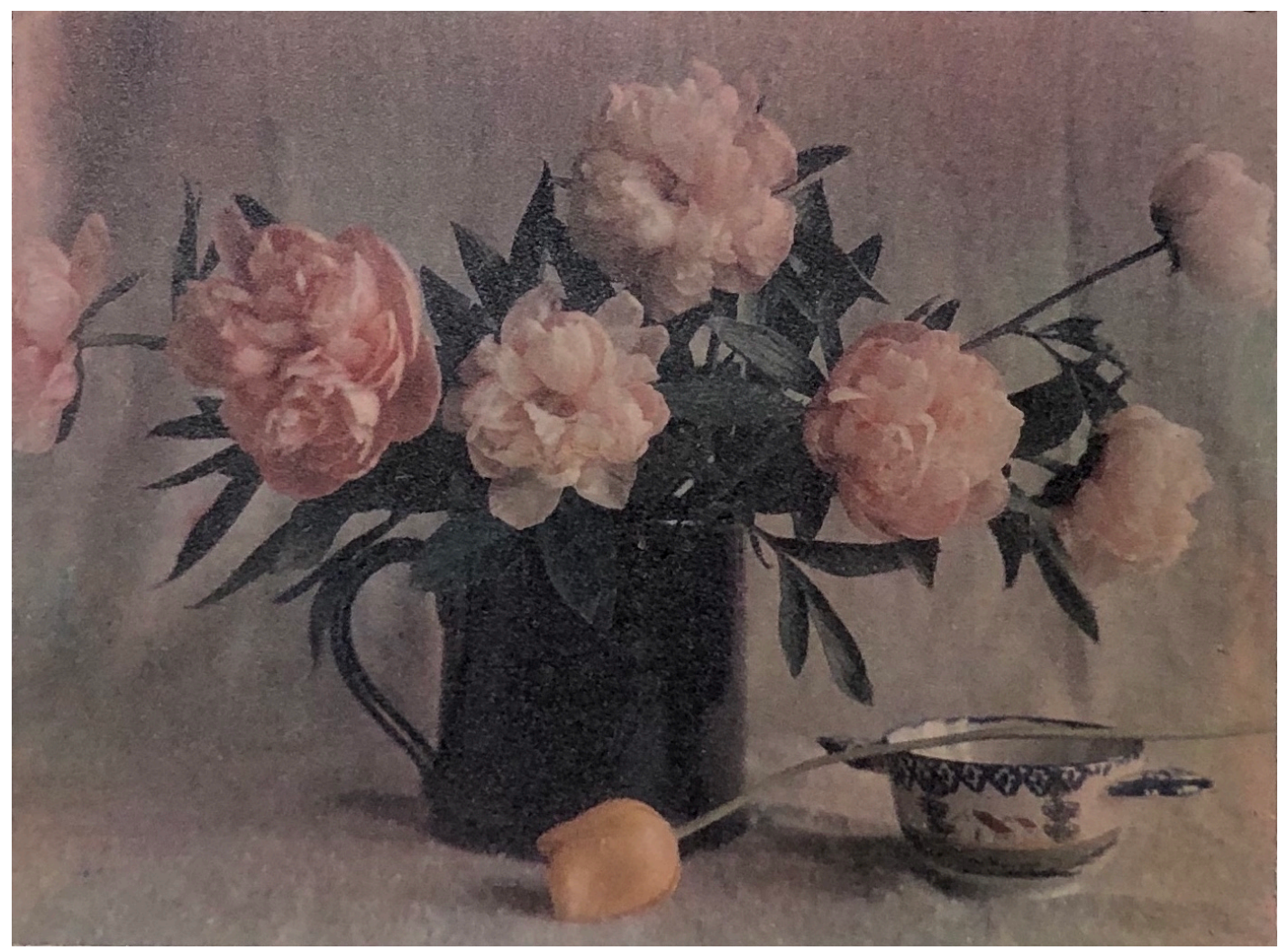

Figure 26. Agnes B. Warburg, Peonies, Raydex/Ozobrome process 1912 (C) Victoria and Albert Museum

\footnotetext{
${ }^{97}$ Coote, The Illustrated History of Colour Photography, 17.

${ }^{98}$ Ibid., 19.
} 
Creating a set of separation negatives required exposing three black and white panchromatic silver emulsions individually through primary coloured filters. "Each filter selectively absorbs all but its own colour, and the light-sensitive emulsion gets exposed only in the areas that are of the same colour as the filter." 99 However, it would be another 40 years before subtractive pigment processes would gain any momentum. Carbon

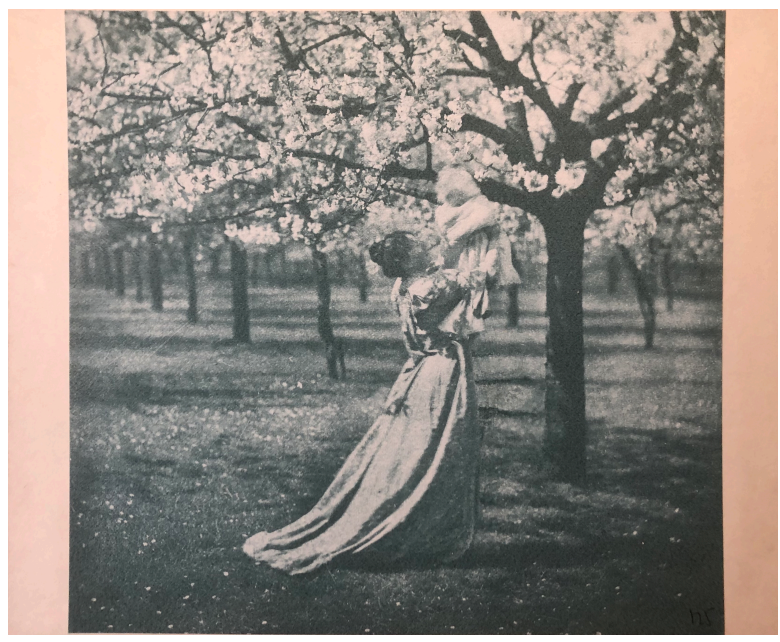

Figure 27. Agnes B. Warburg, Untitled, indigo-tinted carbon print, ca. 1904 (C) Victoria and Albert Museum printing, originally a monochrome process invented by Alphonse Poitevin in 1855, was among the earliest commercially successful pigment processes. ${ }^{100}$ But because panchromatic plate emulsions were not manufactured at the time of his invention, the process would not gain attention in relation to colour printing until much later. Because these processes use pigments as opposed

to dyes, these photographs look almost exactly as they would have when they were made. Warburg began making pigment prints in the earliest part of her career using gum and carbon techniques. However, beginning in 1908 she began to experiment exclusively with tri-colour carbro printing of various types including the Oxobrome/Raydex process and the War-type, which she invented in 1918.

\section{Gum Printing}

Though the gum prints in this collection fall outside the general purview of this discussion, they are central to the emergence of her practice of using colour artistically. The gum printing process was a cornerstone of the pictorialist movement, in part because the final prints often resembled traditional non-photographic fine art prints such as lithographs. Among others, Edward Steichen, Alfred Steiglitz, and Alvin Langdon Coburn were avid users of this process because it allowed for complete control over

\footnotetext{
${ }^{99}$ Penichon, Twentieth Century Colour Photographs, 12

${ }^{100}$ Ibid., 82.
} 
image contrast, density and tone.

The ability to control the final output and select the colour of the pigment suggested a more artistic and evocative final result. Both gum and carbon printing techniques involved re-exposing the original print under one or more layers of pigment suspended in a light-sensitive solution of gum arabic and potassium dichromate. ${ }^{101}$ Early

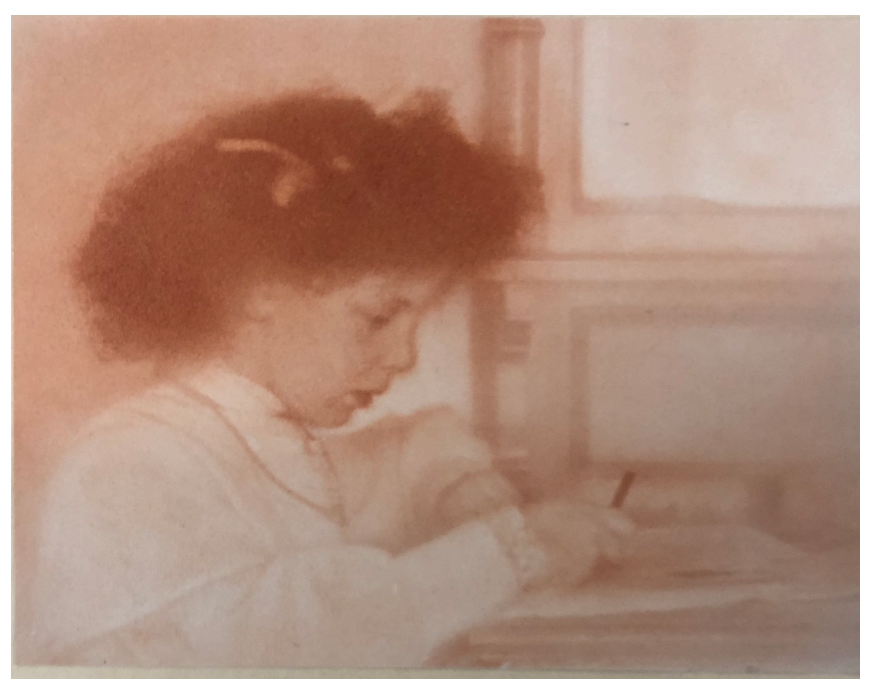

Figure 28. Agnes B. Warburg, Joan E.V. Warburg, sanguine-tinted gum print, ca. 1904 (C) Victoria and Albert Museum

colour historian Pam Roberts identifies that nonprofessional pictorial artist-

photographers, "such as those who experimented briefly with the autochrome," were

primarily among those who took up these complex colour processes on paper. ${ }^{102}$ Roberts notes that in an explosion of self-organized exhibitions, photographers experimented with a multitude of colour mediums, and often referred back to $19^{\text {th }}$ century processes including gum printing, hand-colouring, and cyanotypes. ${ }^{103}$ This characterization describes Warburg exactly.

It is interesting to consider these images within the larger context of her oeuvre and practice. Her early engagement with colour both for personal and exhibition purposes further suggests a dedication to the medium and to the pictorialist movement. Ostensibly, her knowledge about the permanence of the pigment print processes would have informed her later work with tri-colour processes. Given that there was no silver in the top gum layer, these images were significantly more stable than competing technologies, like the autochrome. We can interpret her use of these processes as further evidence for how Warburg's influenced the direction of colour photography. She chose to work with processes that favored the longevity of colour, a favourable characteristic in the amateur circles that were so focused on display.

\footnotetext{
101 Ibid, 60.

${ }^{102}$ Roberts, A Century of Colour Photography, 58.

${ }^{103}$ Ibid, 59.
} 


\section{Tri-colour Carbro}

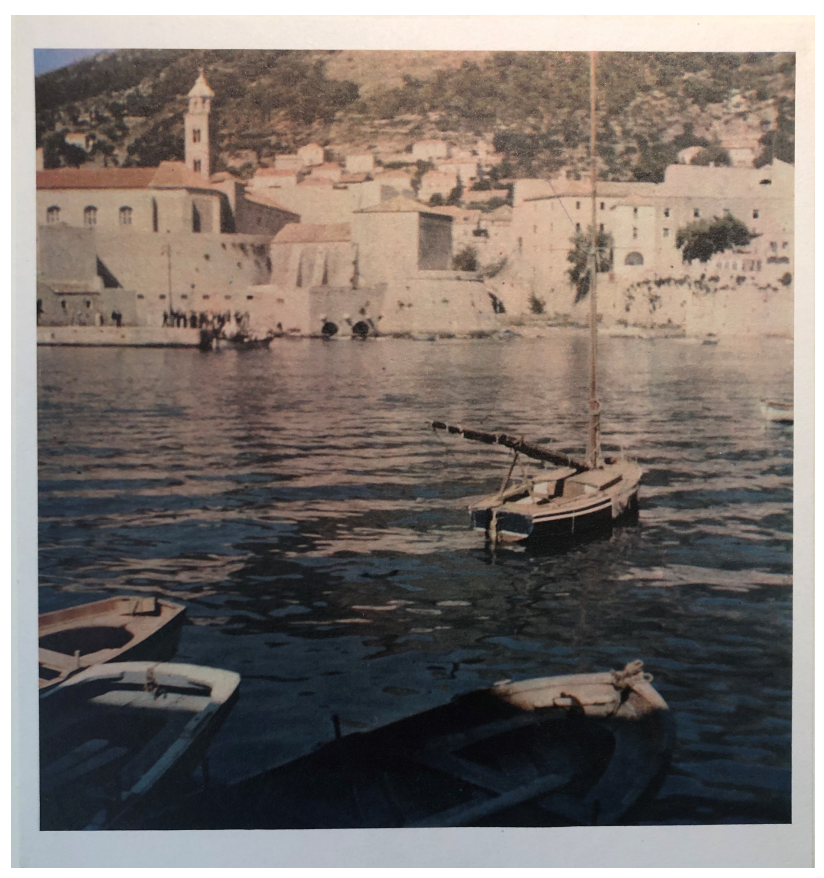

Figure 29. Agnes B. Warburg, Boats in Dubrovnik, tri-colour carbro print from Dufaycolor slide, 1936 C Victoria and Albert Museum
The tri-colour, or three colour, carbro process was the general term used to describe processes that combined carbon-based pigments and silver bromide printing techniques. Warburg used several tri-colour processes, many of which are identified solely as 'tri-colour carbro'. As a result, I will discuss tri-colour carbro generally, and those processes more specifically identified, Raydex/Ozobrome and the War-type, will be discussed in closer detail in the following section. The term 'carbro' was coined by H.F. Farmer (1860-1926) in

1919 and would become the prevailing printing process of the 1930 s due to demand for photographs by magazines and advertising. ${ }^{104}$ The Autotype Company of Ealing manufactured and promoted the tri-colour carbro process until after World War II. In their manual they state, "Anyone who has facilities for making contact, or enlarged bromide prints, and can command a supply of water has all the main essentials for making Carbro prints of any size." 105 In this process three black and white separation negatives taken through coloured filters are contact printed onto silver bromide paper containing no gelatin layer. Each wet bromide print is then contacted printed onto its complementary coloured gelatin coated pigment paper: red negative with cyan paper; green negative with magenta paper; and blue negative with yellow paper. A chemical reaction between the bromide print and sensitized pigment paper ensues - the bromides are bleached and the gelatin in the pigment paper hardens. The whole image has then been transferred onto the pigment papers and the bromide prints can be discarded. The

\footnotetext{
${ }^{104}$ Penichon, Twentieth Century Colour Photograph, 99.

105 The Autotype Company Ltd., "The Carbro Process,” (London: Autotype Company, 1926): 1, accessed July 20, 2019, https://archive.org/stream/carbroprocess00auto/carbroprocess00auto_djvu.txt.
} 
pigment papers are then submerged in warm water to make the gelatin swell in order to create a larger gelatin relief. The resulting reliefs are then rolled onto celluloid supports and left sandwiched together while the gelatin transfers from the paper to the celluloid. The sandwiches are placed in warm water and peeled apart, leaving the image on the celluloid, and the pigment paper is discarded. Once the three celluloid reliefs have dried, they are soaked in water and rolled in sequence - cyan, magenta, yellow - onto a wet temporary paper support. This part of the process is very lengthy, every piece of celluloid must be left in contact with the paper until it dries and separates itself from the paper. After the celluloid comes off, the paper must be rinsed to remove the waxy residue left behind, otherwise the next layer of pigment will not adhere. This process is repeated for each coloured relief. In the final step, the three-colour image is transferred onto a final paper. With both papers wet, the two are sandwiched and pressed together before being put in warm water where the soluble support is peeled from the final paper. ${ }^{106}$ As should be obvious, despite the Autotype Company advertising this process as simple, it was not. It could take days to make a single print.

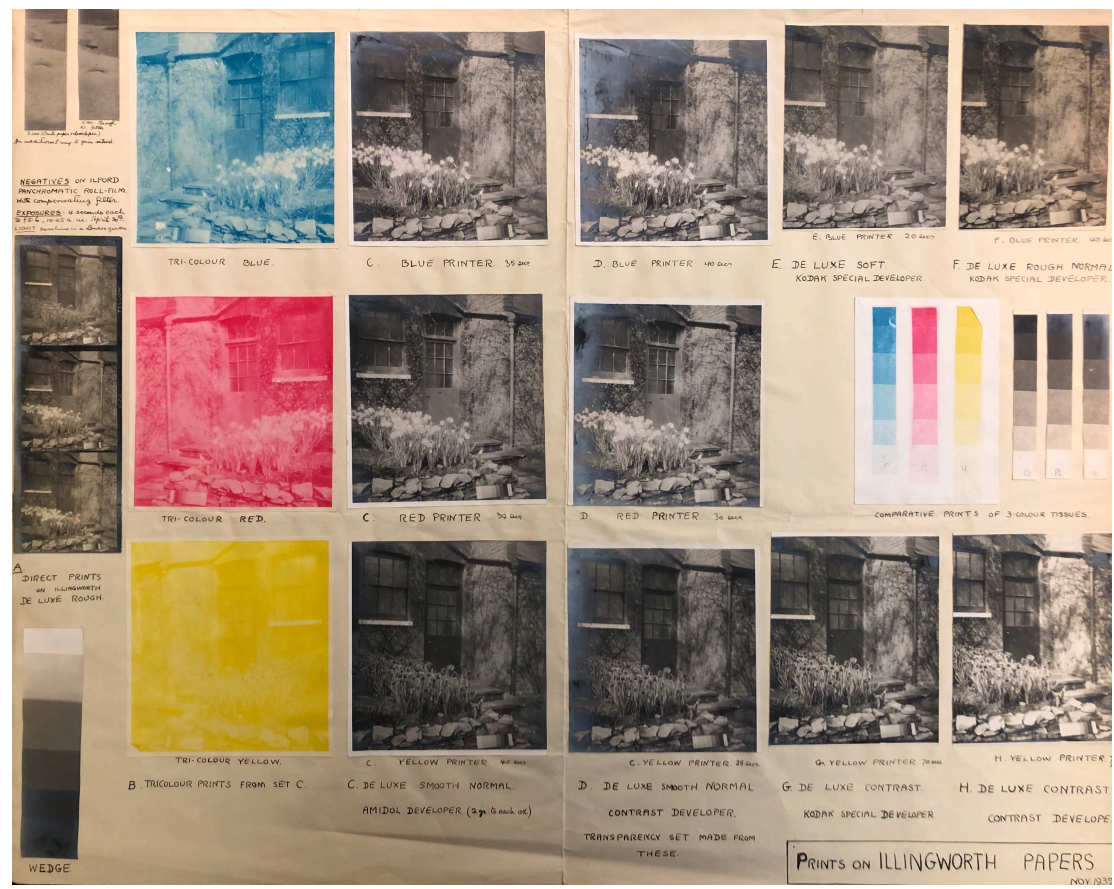

Figure 30. Tri-colour carbro storyboard assembled by Agnes Warburg and used during instructional workshop on the process, 1932 (C) Victoria and Albert Museum

Nevertheless, Warburg became a tri-colour carbro specialist. She was revered in the RPS community for her proficiency at producing prints across a multitude of tri-

\footnotetext{
${ }^{106}$ Penichon, Twentieth Century Colour Photographs, 114-116.
} 
colour processes, hosting lectures and workshops in her home, and around London. In a 1931 RPS lecture titled, "Faults and Failures in Colour Photography: Personal Experiences in Carbro" she charismatically discusses the challenges of the process saying, "I feel little bashfulness in speaking to you to-night, because this evening's subject is a much easier one to talk about than its converse, "Success in Colour Photography", and my own experience of faults and failure is so extensive that I think I am fully competent to deal with it." She goes on to explain that she cannot often explain why things go wrong - that there is an element of magic involved saying that only, "some sort of bewitchment can account for the varied and unexpected results which follow apparently identical courses of procedure."107

To go into detail on all of Warburg's reviews, lectures, and exhibitions is a subject unto itself. This selection of reviews and quotes is intended to provide an overview of how her work was perceived and how she impacted the larger amateur community and consumers of photography. These analyses offer us a clear way to understand her significance within the RPS and foreground the diversity of her practice with colour photography. Considering this breadth of textual material outside the context of the RPS gives both Warburg and her

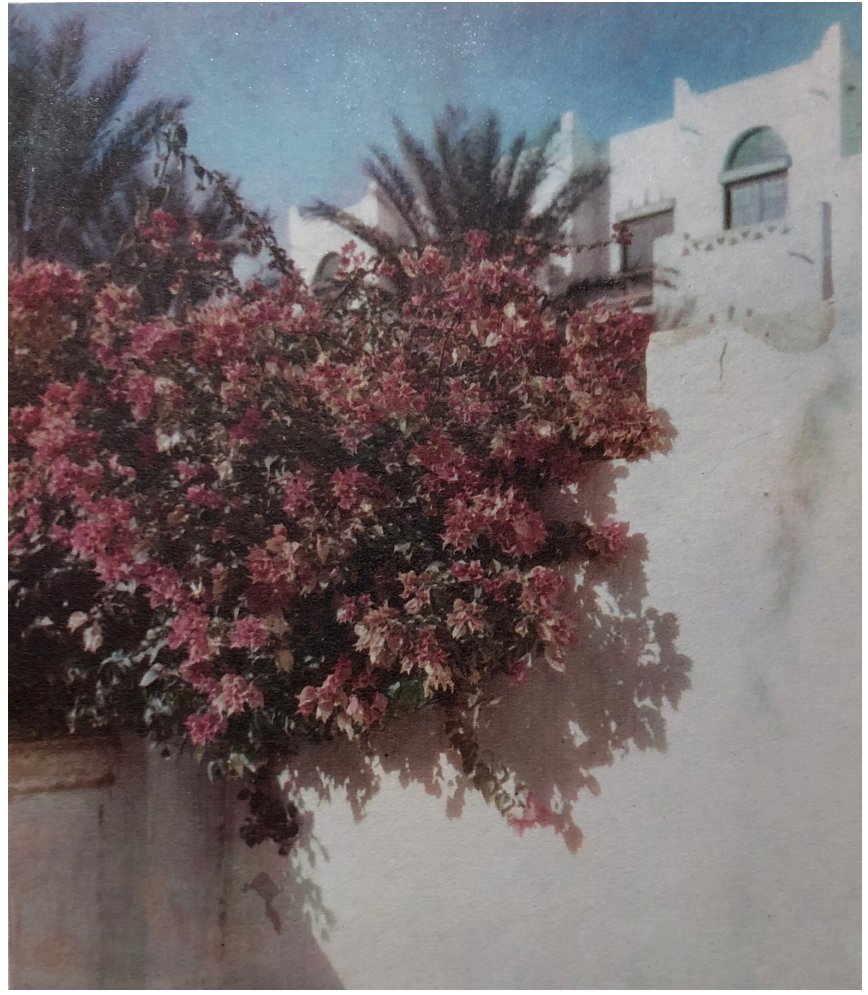

Figure 31. Agnes B. Warburg, Bougainvillea, tri-colour carbro process, ca. 1935 (C) Victoria and Albert Museum photographs new meaning as a significant figure in the history of photography that extends beyond the amateur organizations.

\footnotetext{
${ }^{107}$ Agnes Warburg, "Faults and Failures in Colour Photography: Personal Experiences in Carbro," The Photographic Journal 71 no. 3 (March 1931): 113.
} 


\section{Raydex / Ozobrome}

Thomas Manly, a fellow of the RPS, introduced the Ozobrome process in 1905. Originally released as a monochrome process with twelve different colour options, it was based on carbon printing techniques dating from the late $19^{\text {th }}$ century. ${ }^{108}$ The Ozobrome process was based on carbon printing methods, except it used a bromide print instead of a negative to create the final picture - "the printing is done not by the presence of light but by chemical reaction." "109 Sometimes referred to as the "evening carbon process," the fact that Ozobrome prints could be made without the presence of light was a major selling point of this process. Photographs conservator Sylvie Penichon describes the process: "the pigment paper called 'Ozobrome pigment plaster', was not exposed to light through a negative but was squeegeed firmly to the surface of a wet gelatin silver bromide print immediately after it had been soaked in a sensitizing and bleaching bath, called 'Ozobrome pigmenting solution." ${ }^{110}$ Once the papers were placed together the ensuing chemical reaction took approximately 15 minutes to complete. Similar to the carbro process described in the previous section, this reaction "bleached the bromide and cemented the pigmented gelatin in place relative to the proportion of silver that was present on the image." 111 The bromide print was then removed and the pigment paper squeegeed onto a new paper substrate. The resultant image was turned face down and rested on the top of a warm water to wash away the unhardened gelatin. ${ }^{112}$

In 1913, Samuel Manners purchased the rights to the process and began marketing it as three-colour process called Raydex. It was sold as a complete kit, containing all necessary materials and was considered to be the first colour process that would enable the average amateur photographer to create a colour image. ${ }^{113}$ Manners stated, "Once the bromide prints are made the process becomes automatic, as everything is so systematized that only ordinary care and a little practice are required to produce

\footnotetext{
${ }^{108}$ Penichon, Twentieth Century Colour Photographs, 99.

109 Thomas Manly, "Oxobrome," in The Sinclair Handbook of Photography: A Practical Guide to the Processes of Modern Photography by Leading Experts, (London, UK: James A. Sinclair \& Co., Ltd., 1913), 121.

${ }^{110}$ Penichon, Twentieth Century Colour Photographs, 99.

111 Ibid., 99.

${ }^{112}$ Manly, "Oxobrome," 123.

113 Coe, Colour Photography, 104.
} 
satisfactory results. $" 114$ Raydex materials were available until the late 1920 s when the process was replaced by other tri-colour carbro processes.

Warburg's first tri-colour print was made using the Raydex/Ozobrome process (Figure 32). In annotations on the verso of the prints she specifies the details of the process saying, "My first colour print, by Raydex process; Negatives taken on Wratten Panchromatic plates; taken in sun outdoors on January $29^{\text {th }} 1908$; with a "Videx" with a Zeiss lens at f/6.3. Exposures: blue filter, $16 \mathrm{sec}$; green, $32 \mathrm{sec}$; red, $32 \mathrm{sec}$; developed in Rodinal $1.204 \mathrm{~min}$ at $50^{\circ} \mathrm{F}$." Because the Raydex process was Ozobrome until 1913, I suggest that this, along with several other prints in the collection, was notated retroactively. It is interesting to note that this is one of few times that she references the camera she was using. The Videx reflex plate camera was the best-known camera manufactured by Adams \& Company, London. ${ }^{115}$ It had a built-in tray for colour filters and was designed for plates sized $12 \times 16.5 \mathrm{~cm}$, the approximate size of the "My first colour print." 116
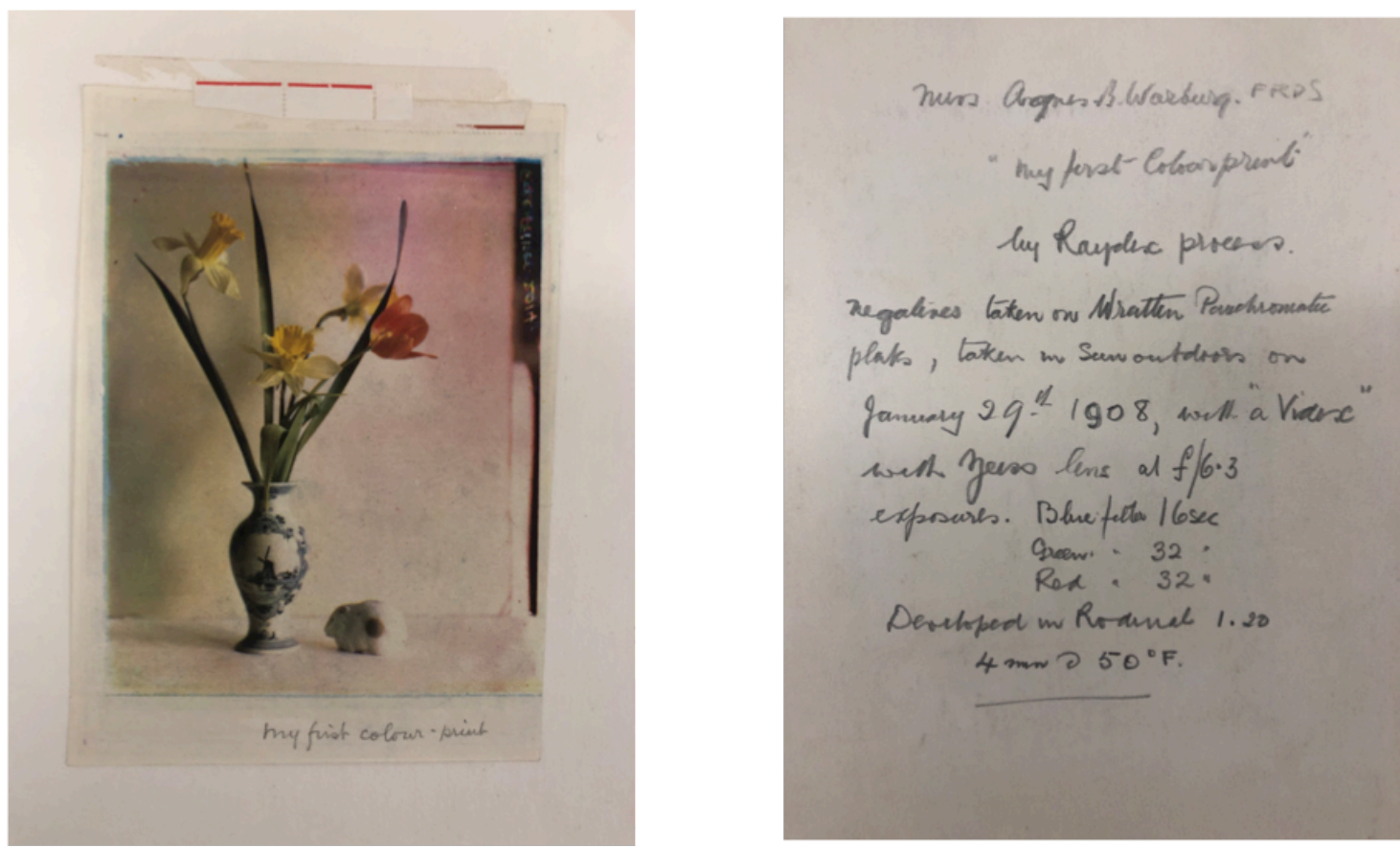

Figure 32. Agnes B. Warburg, My first colour print, Raydex (Ozobrome) process, 1908, C Victoria and Albert Museum

${ }^{114}$ Coote, The Illustrated History of Colour Photography, 76.

115 "Videx Reflex Plate Camera," Historic Camera, last modified June 9, 2015, accessed July 10, 2019, http://www.historiccamera.com/cgibin/librarium2/pm.cgi?action=app_display\&app=datasheet\&app_id=1198 116 "Videx Reflex Plate Camera," Science Museum Group, accessed July 3, 2019, https://collection.sciencemuseum.org.uk/objects/co8085133/videx-reflex-plate-camera-plate-camera 
With the Raydex process Warburg predominantly captured still life and landscape subjects. She displayed these prints in exhibition well into the 1920s, including a selection of prints at the "Graphic and Photographic Art" exhibition in August 1925. Despite the Raydex process sharing so many ties to graphic art production, the reviewer noted that of the works displayed none of them exhibited any "graphic efforts." ${ }^{117}$ Later that year, Warburg's photographs were displayed and reviewed in the $70^{\text {th }}$ annual RPS exhibition. The exhibition critic was fellow photographer Fred Hollyer, and he noted that control of colour prints is "sometimes so obvious, that the prints would be better suited in a watercolour exhibition than a photographic one." "118 The balance of maintaining a pictorial aesthetic without compromising the photographic qualities was clearly difficult to maintain. Hollyer goes on to reinforce pictorial themes, saying that the Raydex process was the best process for accurately reproducing the negative, but that black and white bromoil prints were preferred for depicting more personal expression. ${ }^{119}$ These are only a few examples of many RPS exhibitions in which her photographs were displayed. Of a print displayed at the largest and arguably most important exhibition of the year, the RPS Annual Exhibition, critic and colleague Frank Newens recalls,

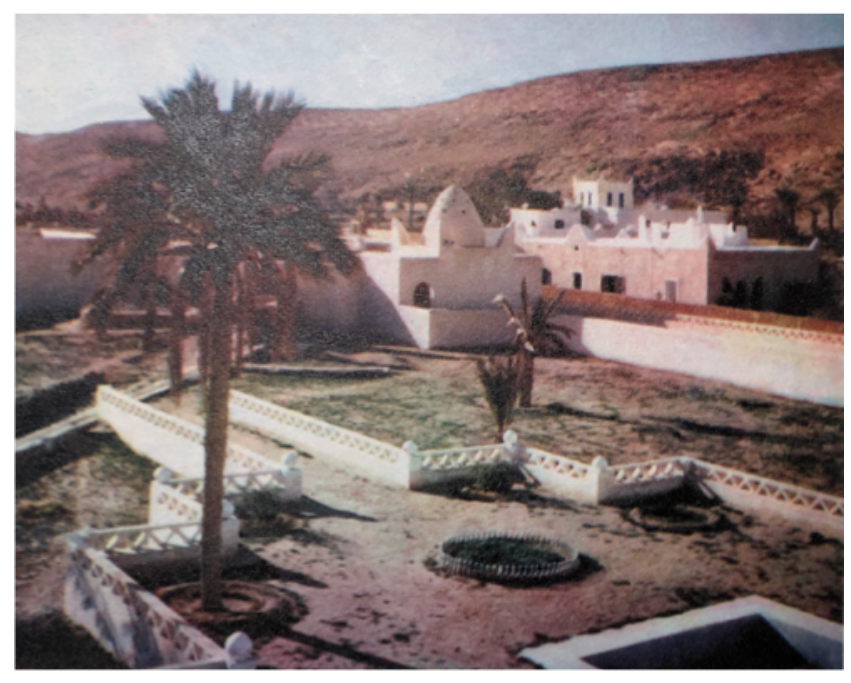

Figure 33. Agnes B. Warburg, Morning in Africa, Raydex print, ca. 1925 (C) Victoria and Albert Museum

"In no. 558 Morning in Africa Miss A.B. Warburg shows her accustomed flair for composition and massing of colour... I always commend her abilities in seeing the pictorial possibilities of the landscape around her." ${ }^{120}$ (Figure 33)

Over the course of nearly three decades that Warburg spent working with colour prints her work was seen and interpreted in different ways, some commending her pictorial work

\footnotetext{
117 J.C. Dollman, “Graphic and Photographic Art," The Photographic Journal 65, no. 8 (August 1925): 421.

${ }^{118}$ Fredrik Hollyer, "The Charm of Colour: A Review of the Pictorial Prints and Transparency Section," The Photographic Journal 65, no. 10 (October 1925): 67.

119 Ibid., 67.

${ }^{120}$ Frank Newens, “Colour Prints and Transparencies: Raydex," The Photographic Journal 74, no. 11 (November 1934): 494.
} 
in colour and others not. What is clear however, is her commitment to tri-colour printing despite the difficulties that accompanied both the prints production and public reception. Evidently, she was not concerned with how her photographs fit into the institutional and museum models of fine art and was content with existing within the amateur sphere and making art for art's sake.

\section{War-type}

Warburg invented her own process, the War-type in 1918. The process was published in the October issue of the British Journal of Photography's Colour Supplement, but like many colour processes that came to fruition during this time, it did not gain traction commercially. However, her invention of this process represents the crux of this research - it allows us to situate Warburg alongside other influential manufacturers and scientists who were working towards the same goal of making colour accessible to all. As stated in the article, her motivation to develop this process stemmed

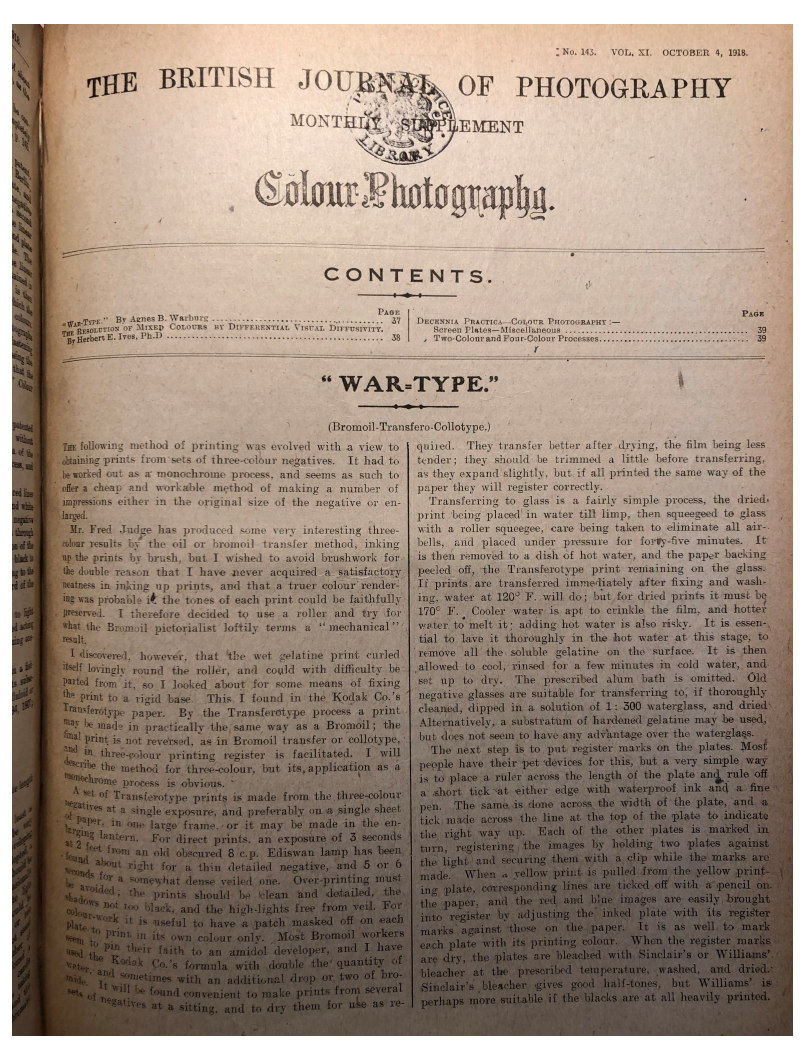

Figure 34. "War-type," British Journal of Photography: Colour Supplement 11, (No. 134 October 4, 1918): 37. from dissatisfaction with other tri-colour processes. Though the War-type was never manufactured or used commercially, it is emblematic of her significance within history insofar as it represents her efforts to shape the development of colour photography, and again, it establishes the importance of the study of amateurism when considering the history of colour photography during this time period.

The War-type was a 'bromoiltransfero-collotype'. Like most other three colour processes it involved the use of separation negatives, but also 
involved the commercial, photomechanical collotype process that was invented by Alphonse Poitevin in 1856. The collotype was used to mass-produce black and white prints and in theory, integrating this process would make the War-type a cheaper and more workable printing process. ${ }^{121}$ The multi-step War-type process required transferring three sets of colour reliefs onto a final paper substrate. Where a normal tri-colour print would use a silver bromide print to transfer onto pigment papers, War-type used bromoil prints - an alternative that had been tested by her RPS colleague Fred Judge. Warburg notes that Judge brushed the bromoil solution onto the papers and Warburg did not like this technique for two reasons. Warburg states, "I have never acquired a satisfactory neatness in inking up prints, and that a truer colour rendering was probably if the tones of each print could be faithfully preserved. I therefore decided to use a roller and try for what the Bromoil pictorialist loftily terms a "mechanical" result." 122 However, in doing this Warburg found that the "wet gelatin paper curled itself lovingly round the roller and could with difficulty be parted from it." ${ }^{, 123}$ In order to limit the problem she used Kodak's Transferotype papers, which came fixed onto a rigid base. The process is described in great detail: exposure times for negatives; her experiences with various developers and why she uses what she does; and the step-by-step process for creating a War-type image including her personal tips. Unfortunately, War-type images are not directly identified in the collection, nor were they featured in any exhibitions under their process name, instead likely listing themselves as 'tri-colour print[s].'

\footnotetext{
${ }^{121}$ Agnes B. Warburg, "War-type,” British Journal of Photography: Colour Supplement 11, no. 134 (October 4, 1918): 37.

${ }^{122}$ Warburg, "War-type," British Journal of Photography, 37.

123 Ibid., 37.
} 


\section{Conclusion}

To understand Agnes Warburg's photographs and practice is to understand the many facets that made up her career. Through her extensive work with nine processes (and possibly more), participation in salon exhibitions in the UK, and her deep involvement in the Royal Photographic Society's Colour Group, this paper has identified her as an important early 'colour photographer' dedicated to seeing photographically in colour. This paper has served as an entry point into her life and work, as well as opened up some broader ideas around the significance of amateurism in Britain and the RPS community. This paper demonstrates role that amateur photographers played in perpetuating the development of colour photography across its uses, and as such, enables us to understand how photographers like Warburg shaped the artistic and scientific landscape of colour photography. Warburg was an unusual and eccentric woman with few interests outside of photography. She and the individuals she associated with carried a distinct set of values centered on personal and photographic sociability that was enmeshed with artistic, cultural and scientific significance. In choosing her path as an amateur, Warburg was able to carry out her personal aspirations for the medium irrespective of reward or acknowledgement. The Colour Group and the RPS gave her a platform in which to disseminate her vast photographic knowledge and values, without a doubt leaving a lasting impact on those who she taught, inspired and supported in making colour photographs.

Warburg was a transitional figure whose career is emblematic of colour photography's technical and artistic evolution between 1907 and 1945. She began by making quintessentially pictorial photographs using black and white materials and quickly progressed to become one of only a few photographers dedicated to seeing that colour photographs enter the pantheon of fine arts in the early 1900s. Her approach to photographing and printing in colour enriched the pictorialist iconography of still life and landscapes through a varied approach to process, and a continuously evolving approach to her subjects. Her work subtly evokes a different type of pictorialism by demonstrating an awareness of human presence that is not otherwise seen in the works of her contemporaries working with colour artistically. Later in her career, as a result of new 
and better forms of photographic technology and an awareness of photographic trends, she bridged the romantic, art-minded structures of pictorialism with notions of 'straight' and documentary photography. However, my claim about her influence may have looked quite different had she not been so wealthy: more likely than not, she would have had to work commercially, limiting her artistic exploration with colour and perhaps changing the scope of her impact. Further research into her personal inspirations and network is required in order for us to gain a clearer idea of what was informing her choices, work methods and personal motivations.

This research has illuminated the breadth of opportunity for discovery within the RPS collections of early colour work. This research has attempted to shed light onto photography's dark ages - the period between the autochrome in 1907 and Kodachrome in 1935. This was a time fraught with chaos and challenges within the fields of colour photography but also great excitement, diversity and collaboration. Through investigation of Warburg's practice using platinum, carbon, gum arabic, the War-type, Raydex/Ozobrome, autochrome, Dufaycolor, additive screen printing, Colorsnap, and miscellaneous other tri-colour processes, we gain an understanding of a portion of the diversity of activity and the climate of experimentation taking place within this time period. Furthermore, we come to understand both the technicalities of these processes and the social environment she was working in, which bolstered her ability to pursue such a wide range of activities. By virtue of her role as a founder of the Colour Group, she was privy to every aspect of colour photography's evolution during that thirty-year period. She had no interest in having her work acquired or displayed by a museum, because to her 'colour photography' was more than simply capturing or creating a pictorial scene, and broader than its commercial associations that limited it to print and advertising. The Colour Group and the RPS allowed her to pursue colour photography on her own terms, and subliminally, she characterized the term 'colour photographer' within the field of photography.

Her work and life appear to have been tightly interwoven with the RPS and as a result, more research into the interconnectivity of the RPS Colour Group and the public 
and professional networks surrounding colour photography could further elaborate Warburg's biography and our understanding of her work. This would be further supported by investigation into the collections of work made by Colour Group members in the RPS collection at the V\&A, including Frank Newens, F.G. Tutton, and Violet Blaiklock (to name only a few). This paper serves as a good first step towards getting to know a collection that is only in its earliest days of research. The unprecedented access offered by the V\&A has breathed new life into RPS collection and gradually, as researchers continue to unpack the seemingly limitless opportunities within the early colour collections at the V\&A, we will gain a better understanding of what I have started here.

When refiguring the predominant photographic history of colour, it is essential to account for the huge range of activities undertaken by expansive groups like the RPS that perpetuated much of the success in photography's technical and artistic evolution. Warburg's selective oeuvre offers those of us studying her work her very best examples. There are no duplicates - her faults and failures not captured in the collection despite mistake and experimentation being inseparable from the time period. Like many photographers that came before and after her, she destroyed a selection of her photographs before death in order to self-identify and memorialize her career. It is my hope that by considering Agnes Warburg and her photographs outside the confines of the RPS network, I have been able to bring her dynamic character and photographs to light, and establish her significance within the larger history of photography. 


\section{Bibliography}

\section{Books}

Coote, Jack H. The Illustrated History of Colour Photography. Surrey, UK: Fountain Press Limited, 1993.

Hirsch, Robert. Exploring Color Photography. Madison, WI: Brown \& Benchmark, 1993.

Gamble, William Burt. Color Photography: A list of references in the New York Public Library. New York, NY: New York Public Library, 1924. Accessed July 15, 2019. https://archive.org/details/colorphotography00newy/.

Lavédrine, Bertrand and Jean-Paul Gandolfo. The Lumiere Autochrome: History, Technology and Preservtion. Los Angeles: Getty Conservation Institute, 2013.

Pénichon, Sylvie. Twentieth Century Colour Photographs: Identification and Care. Los Angeles, CA: Getty Conservation Institute, 2013.

Sipley, Louis Walton. A Half Century of Colour. New York, NY: MacMillan, 1951.

Spencer, D.A. Colour Photography in Practice. New York, NY: Pitman Publishing Corporation, 1948.

Warburg, Frederic. An Occupation for Gentlemen. London, UK: Hutchinson, 1959.

Wilhelm, Henry and Carol Bower. The Care of Color Photographs: Traditional and Digital Color Prints, Color Negatives, Slides and Motion Pictures. Self-published, Kingsport, TN: Wilhelm Imaging Research, 1993.

Wood, John. The Art of the Autochrome: The Birth of Color Photography. Iowa City, IA: University of Iowa Press, 1993.

\section{Book Chapters}

Boulouch, Nathalie. "Autochromes and Pictorialism: An Element of Colour in a Monochrome Universe." In Impressionist Camera Pictorial Photography in Europe, 1888-1918, edited by Patrick Daum and Phillip Prodger, 269-283. London, UK: Merrell Publishers Limited.

Hostetler, Lisa. "Real Color." In Color Rush: American Color Photography from Stieglitz to Sherman, 20-27. New York, NY: Aperture Foundation and the Milwaukee Art Museum, 2013.

Joschke, Christian. "Amateurism and Cultural Change: Photography in Germany and Austria (1880-1900).” In Impressionist Camera Pictorial Photography in Europe, 
1888-1918, edited by Patrick Daum and Phillip Prodger, 107-112. London, UK: Merrell Publishers Limited, 2006.

Manly, Thomas. "Oxobrome." In The Sinclair Handbook of Photography: A Practical Guide to the Processes of Modern Photography by Leading Experts, 121-124. London, UK: James A. Sinclair \& Co. Ltd.,1913.

Roberts, Pamela. "Alternatives to the Autochrome, 1900-1930." In A Century of Colour Photography: From the Autochrome to the Digital Age, 20-55. London, UK: Andres Deutsch Limited, Carlton Publishing Group, 2007.

"The Autochrome." In A Century of Colour Photography: From the Autochrome to the Digital Age, 56-77. London, UK: Andres Deutsch Limited, Carlton Publishing Group, 2007.

Rosenblum, Naomi. "Biographies." In A History of Women Photographers, 320-330. New York, NY: Abbeyville Press Publishing Group, 1994.

Wall, E.J.. "Introduction." In Color Photography: A list of references in the New York Public Library, 4. New York, NY: The New York Public Library, 1924.

Williams, Val. "Photography in Transition: An Overview (1840-1939)." In Women Photographers: The Other Observers, 1900-present, 11-24. London: Virago, 1986.

\section{Journal Articles}

Dollman, J.C. "Graphic and Photographic Art." The Photographic Journal 65, no 4. (August 8, 1925): 421.

Fuchs, Caroline. "Anticipation and Reality: A reevaluation of Autochrome Projection." PhotoResearcher, no. 19 (2013): 33-42.

Hewitt, Edward R. "The Making and Projection of Autochrome Plates." The Photographic Journal 67 (1927): 493-95.

Hollyer, Fredrik. "The Charm of Colour: A Review of the Pictorial Prints and Transparency Section.” The Photographic Journal 65, no. 10 (October 1925): 67.

Lumière, Auguste, and Louis Lumière. "La Photographie de Couleurs, Ses Methodes et Ses Resultats".” Revue Générale de Des Sciences Pures et Appliquées 23: (1895): 1034.

The Royal Photographic Society. "Colour Work at the RPS Exhibition: Informal Meeting of the Colour Group.” The Photographic Journal 67: (1927), 496-97. 
Newens, Frank R. "Colour Prints and Transparencies: Raydex." The Photographic Journal 74, no. 11 (November 1934): 494.

"Obituary: Agnes B. Warburg (Fellow)." Royal Photographic Society Journal 93, no.3 (March 1953): 111.

Roberts, Pam. "The Royal Photographic Society Collection: A Companion to the Photographic Journal.” The Photographic Journal Times 134 (10), 1994.

Stieglitz, Alfred. "The New Color Photography - A Bit of History." Camera Work: 20 (October 1907). Accessed November 30, 2018. http://www.photocriticism.com/members/archivetexts/photocriticism/stieglitz/stie glitzcolor.html

Stebbins, Robert A. "The Amateur: Two Sociological Definitions." The Pacific Sociological Review 20, no. 4 (October 1977): 582-606.

Vaughn, Fiona. "Dufaycolor: materials, techniques and deterioration." The Australian Institute for the Conservation of Cultural Materials (AICCM) Bulletin 31, (2008): 53-65.

Warburg, Agnes B. "War-type." The British Journal of Photography: Colour Supplement 143, no. 11 (October 4, 1918): 37-38.

"Three-Colour Carbro: To the Editors." The British Journal of Photography 74, no. 3507 (July, 1927): 439.

"Faults and Failures in Colour Photography: Personal Experiences in Carbro." The Photographic Journal 71 no. 3 (March 1931): 113-117.

"Highland Holiday." The Photographic Journal 161, no. 7 (July 1937): 438.

Wheeler, Owen. "Colour Photography: The Exhibition Reviewed." The Photographic Journal 72, no. 1 (January 1932): 1-5.

\section{Websites}

Bjelkhagen, Hans I. "Lippmann Photography: its history and recent development." Holography Forum. Accessed July 7, 2019 https://www.holographyforum.org/ data/lippmann/Bjelkhagen-Lippmann_Photography.pdf

Edwards, Elizabeth, "The Amateur Excursion and the Social Production of Photographic Knowledge." Reconsidering Amateur Photography. Accessed July 29, 2019. http://eitherand.org/reconsidering-amateur-photography/amateur-excursion-andsociable-production-photogra/ 
Flükiger, Barbra. "Dufaycolor." Timeline of Historical Colours. 2012. Accessed February 15, 2019. https://zauberklang.ch/filmcolors/timeline-entry/1257/?_sf_s=dufay

Freestone, Janine. "Cliché in the Making: Sunsets in Early Colour Photography." Reconsidering Amateur Photography. Accessed July 29, 2019. http://eitherand.org/reconsidering-amateur-photography/cliche-making-sunsetsearly-colour-photography/

Jobey, Liz. "A Rummage through the V\&A's New Photography Collection.” The Financial Times, January 26, 2018. Accessed July 6, 2019. https://www.ft.com/content/f98c4860-0096-11e8-9650-9c0ad2d7cs5b5.

Historic Camera. "Videx Reflex Plate Camera.” Last modified June 9, 2015. Accessed July 10, 2019. http://www.historiccamera.com/cgibin/librarium2/pm.cgi? action=app_display\&app=datasheet\&app_id $=1198$

Pasternak, Gil. "Photographic Histories, Actualities, Potentialities: Amateur Photography as Photographic Historiography." Reconsidering Amateur Photography. Accessed June 30, 2019. http://eitherand.org/reconsidering-amateurphotography/photographic-histories-actualities-potentialities-/

Pritchard, Michael. "Our Story.” The Royal Photographic Society. Accessed June 30, 2019. http://rps.org/about/history/history-of-the-rps

Pritchard, Michael. "Who were the amateur photographers?" Reconsidering Amateur Photography. Accessed June 30, 2019. http://eitherand.org/reconsideringamateur-photography/photographic-histories-actualities-potentialities-/

Science Museum Group. "Videx Reflex Plate Camera.” Accessed July 3, 2019. https://collection.sciencemuseum.org.uk/objects/co8085133/videx-reflex-platecamera-plate-camera

\section{Manuals}

The Autotype Company Ltd. “The Carbro Process," (London: Autotype Company, 1926) 1. Accessed July 6, 2019. https://archive.org/stream/carbroprocess00auto/ carbroprocess00auto_djvu.txt.

Carson, W.H. “The English Dufaycolor Film Process.” (London: Dufaycolor Ltd., July 1934).

Dufaycolor Company Inc. "The Dufaycolor Manual of Interest to Advanced Amateurs, Professional Photographers and Printers.” (New York: Dufaycolor Inc. 1938). 


\section{Manuscripts}

Minutes of the Royal Photographic Society Colour Group. "Bylaws of the Colour Group.” April 1927, Royal Photographic Society Collection at the Victoria and Albert Museum, XRA 84.

Museum of Modern Art (MoMA), "Master Checklist." From the exhibition Photography 1839-1937, 1937 119-120. Accessed July 7, 2019, https://www.moma.org/documents/moma_master-checklist_387256.pdf

Warburg, Agnes. "Highland Holiday Explained." Hand-written notes dated 1927. Royal Photographic Society Collection at the Victoria and Albert Museum, XRG 194.

\section{Appendix}

The Victoria and Albert Museum, "The V\&A box list of glass-based photography in the Royal Photographic Society Collection.” https://vanda-productionassets.s3.amazonaws.com/2018/05/02/14/25/01/465befda-76b2-4bf0-8935$7 \mathrm{c} 7 \mathrm{~d} 8 \mathrm{be} 7739 \mathrm{~d} / \mathrm{XRG} \% 20$

The Victoria and Albert Museum, "The V\&A box list of paper-based photography in the Royal Photographic Society Collection.” https://vanda-productionassets.s3.amazonaws.com/2018/05/02/14/21/38/b72fffba-ba46-4aa2-bfbb5eaa0e817a7c/XRP\%20Box\%20list\%20for\%20PDF\%20ER\%20and\%20DC\%20e dits.pdf 